\title{
Associations to unfamiliar words: Learning the meanings of new words
}

\author{
ROGER CHAFFIN \\ Trenton State College, Trenton, New Jersey
}

\begin{abstract}
Five experiments were designed to examine whether subjects attend to different aspects of meaning for familiar and unfamiliar words. In Experiments 1-3, subjects gave free associations to high- and low-familiarity words from the same taxonomic category (e.g., seltzer:sarsparilla; Experiment 1), from the same noun synonym set (e.g., baby:neonate; Experiment 2), and from the same verb synonym set (e.g., abscond:escape; Experiment 3). In Experiments 4 and 5, subjects first read a context sentence containing the stimulus word and then gave associations; stimuli were novel words or either high- or low-familiarity nouns. Low-familiarity and novel words elicited more nonsemantically based responses (e.g., engram:graham) than did high-familiarity words. Of the responses semantically related to the stimulus, low-familiarity and novel words elicited a higher proportion of definitional responses [category (e.g., sarsparilla:soda), synonym (e.g., neonate:newborn), and coordinate (e.g., armoire: dresser)], whereas high-familiarity stimuli elicited a higher proportion of event-based responses [thematic (e.g., seltzer: glass) and noun:verb (e.g., baby:cry)]. Unfamiliar words appear to elicit a shift of attentional resources from relations useful in understanding the message to relations useful in understanding the meaning of the unfamiliar word.
\end{abstract}

People are continually learning the meanings of new words. Most are picked up casually from the context, without the help of a formal definition (Jenkins, Stein, \& Wysocki, 1984; Nagy, Anderson, \& Herman, 1987; Nagy, Herman, \& Anderson, 1985; Shu, Anderson, \& Zhang, 1994; Stahl, 1991; Sternberg, 1987). How this is accomplished is something of a mystery given the extent of the explicit instruction required for school children to learn new words (McKeown, Beck, Omanson, \& Pople, 1985). One strategy that might facilitate the learning of new words would be to attend to aspects of meaning for unfamiliar words that are different from aspects of meaning for familiar words. Young children appear to do this (Markman \& Hutchinson, 1984; Markman \& Wachtel, 1988; Waxman \& Gelman, 1986). Adults may use a similar strategy. This hypothesis was examined in five experiments in which subjects gave associations to familiar, unfamiliar, and novel words. If unfamiliar words elicit a shift of attention to aspects of word meaning different from those attended to for familiar words, then we might expect to find different types of associations to familiar and unfamiliar words.

Consider the process of understanding a sentence containing an unfamiliar or novel word. For example,

This work was supported by a Research Award from Trenton State College. The author would like to thank Liana Appleberg, Angela Ellis, and Genevieve Harley for assistance in conducting the experiments, and Mary Crawford and Leslie Caplan for comments on an earlier version of this paper. Correpondence should be addressed to R. Chaffin, Department of Psychology, Trenton State College, Trenton, NJ 08650 (e-mail: chaffin@tcnj.edu).
The sportsman held the record for the

$$
\text { biggest }\left\{\begin{array}{l}
\text { salmon } \\
\text { sturgeon } \\
\text { bransion }
\end{array}\right\} \text { caught in the state. }
$$

To understand Sentence 1, one must understand the thematic relations of salmon, sturgeon, or bransion to the verb catch and its agent sportsman. This understanding must be related to knowledge about the practices of sports fishermen to understand the event described in the sentence. I will refer to semantic relations between words linked by an event (e.g., salmon:sportsman, and salmon: catch in Sentence 1) as event-based relations. If Sentence 1 contains a familiar word, salmon, then the reader's task is simply to understand the proposition expressed, information carried largely by event-based relations. On the other hand, if Sentence 1 contains an unfamiliar word, sturgeon, or a novel word, bransion, then the reader has the additional task of inferring what kind of thing a sturgeon or a bransion is. The reader must infer that a bransion is a kind of fish. I will refer to semantic relations that answer the question, "What kind of thing is it?" (e.g., bransion:fish and salmon: $f(i s h)$ as definitional relations. If Sentence 1 contains a novel word, then the reader must try not only to understand the proposition expressed but to infer a definitional relation between bransion and some familiar concept, such as fish.

The task of understanding a proposition and the task of inferring the meaning of an unfamiliar word may call on somewhat different sets of semantic relationships. One possibility is that people will pay more attention to definitional relations for unfamiliar words than for familiar words. According to this definition hypothesis, the most 
salient information about an unfamiliar word is what kind of thing it refers to. If this is the case, we might expect to find a higher proportion of definitional associations for unfamiliar words than for familiar words. Another possibility is that people pay more attention to event-based relations for unfamiliar words. According to this eventbased hypothesis, event-based relations are necessary to understanding the meaning of an unfamiliar word. To infer the meaning of the novel word bransion, the reader must understand the thematic relations of bransion to catch and to sportsman and map these relations onto knowledge about sports fishing before any inference is possible about the meaning of bransion. On this view, these event-based relations will be more available than the definitional relation bransion: fish, which was never directly encountered but must be inferred. If this is the case, we might expect to find a higher proportion of eventbased associations for unfamiliar words than for familiar words.

Differences in associations to familiar and unfamiliar words could occur as the result of differences in the degree to which familiar and unfamiliar words activate associative links with event-based and definitional information. Such differences could result from differences in memory representation or from differences in processing of familiar and unfamiliar words. For example, memory differences would occur if, when a word is first encountered, event-based links are established before definitional links, or vice versa. A processing difference would occur if unfamiliar words elicit a temporary shift of attention to definitional or event-based aspects of the words' meanings. Such differential activation could be the result of a strategy learned through schooling (Cole, 1990; Rogoff \& Chavajay, 1995) or of a constraint on learning that operates from the early stages of first-language acquisition (Markman, 1989; Markman \& Hutchinson, 1984; Markman \& Wachtel, 1988; Waxman \& Gelman, 1986).

Two considerations suggest that an association task might be sensitive to effects of familiarity on the probability of definitional and event-based responses. First, people have a partial knowledge of the meanings of low familiarity words, and this knowledge appears to be reflected in the associative responses they give to these words (Durso \& Shore, 1991). Second, the proportion of definitional and event-based responses in association data varies systematically as a function of several variables related to level of education. Preschool children show a shift from thematic to superordinate category associates with age (Entwisle, 1966). Adults show consistent individual differences in the frequency with which they produce definitional (category and synonym), event-based, and antonym responses (Moran, Mefferd, \& Kimble, 1964). There are also differences between age cohorts, countries, and social classes. The proportion of category responses in U.S. data declined substantially during the first half of this century (see Jenkins \& Russell, 1960). Category responses are given less frequently by French subjects than by U.S. subjects and less frequently by students than by workers (Rosenweig, 1970).
While a number of studies have varied frequency in word association tasks (Cramer, 1968, pp. 56-63), only one has examined its effect on the type of response. Deese (1962) collected associations to words varying in frequency. Responses were classified by form class (noun, verb, adjective, adverb). Deese found no relation between frequency and the proportion of same-form-class ( paradigmatic) and different-form-class (syntagmatic) responses to noun, verb, or adverb stimuli. (The only effect was for adjectives.) These results leave open the question of whether or not familiarity affects the proportion of event-based and definitional associations. While many defining relations obtain between two words of the same form class (e.g., bird:robin), so do many event-based relations (e.g., farmer:tractor). Although the paradigmatic/ syntagmatic distinction is related to the distinction between definitional and event-based relations, Deese's procedure did not provide a test of the present hypothesis.

Deese's (1962) treatment of his data differed in a second important way from that used in the present inquiry. The present hypothesis concerns the proportion of semantically related responses that are definitional or event-based. Subjects who do not know the meaning of a stimulus word are likely to give nonsemantically related responses (e.g., rhymes). Semantically related responses of all types are, therefore, likely to be more frequent for high-familiarity stimuli than for low-familiarity stimuli. The question is whether the proportion of these responses that are definitional or event-based differs for high-and low-familiarity words. The probability of the different relation types will, therefore, be examined as a proportion of the number of semantically related responses rather than as a proportion of all responses. Deese did not distinguish responses that were semantically related to the stimulus from those that were not.

In the experiments described below, high- and lowfamiliarity words were equated for concreteness and other semantic properties by selecting pairs of words that varied in familiarity but were otherwise similar in meaning. In Experiments 1-3, subjects simply gave associations to high- and low-familiarity words. In Experiment 1, pairs of words were selected from the same category. In Experiments 2 and 3, pairs of synonyms were selected-nouns in Experiment 2, verbs in Experiment 3. In Experiments 4 and 5, subjects first read a context sentence, such as Sentence 1 above, that contained a target word. They then gave associations to the target word that was either novel or a high- or low-familiarity coordinate, as in Experiment 1.

\section{EXPERIMENT 1}

\footnotetext{
Method

Materials. A preliminary selection of 150 words was made from 31 categories in the Battig and Montague (1969) category norms. At least one high-familiarity member and one low-familiarity member were selected from each category, with up to eight members being selected for some categories. The pairs were randomly ordered and presented to 15 subjects, who rated them for familiarity on a 4-point scale labeled extremely familiar (4), moderately famil-
} 
iar (3), moderately unfamiliar (2), and extremely unfamiliar (1). On the basis of these ratings, 24 pairs of experimental stimuli were selected from different taxonomic categories, a high-familiarity word and a low-familiarity word for each category. The high-familiarity words were rated as extremely familiar $(M=3.88)$, whereas the low-familiarity words were rated as moderately to extremely unfamiliar $(M=1.58)\left[t(23)=16.23, S E_{\mathrm{D}}=0.69\right]$. The mean written frequency of the high-familiarity experimental stimuli $(M=6.67)$ was higher than that of the low-familiarity stimuli $(M=1.08)$ $\left[t(24)=3.13, S E_{\mathrm{D}}=8.75 ;\right.$ Francis \& Kučera, 1982]. (This difference in frequency may be assumed to account for the difference in familiarity.) Item dominance (production frequency in the Battig \& Montague, 1969, category norms) was approximately equal for the high-familiarity stimuli $(M=4.42)$ and the low-familiarity stimuli $(M=6.17)\left[t(24)=1.30, S E_{\mathrm{D}}=6.58\right]$.

An additional 24 familiar filler words were selected, each from a different taxonomic category not otherwise represented by the stimuli; 19 came from categories in the Battig and Montague norms. The mean written frequency of the filler items was higher than that of the high-familiarity experimental stimuli $(M=35.42, S D=$ 92.62). The stimuli are listed in Appendix A.

Two lists were prepared, each containing both high- and lowfamiliarity experimental words and the 24 filler words. Familiarity was counterbalanced across lists so that each experimental category was represented once on each list. Each list began with two warmup items.

Procedure. The items were randomly ordered and presented to the subjects in booklets. The same order was used for all subjects The subjects were told that all of the stimuli were nouns. They were instructed to read each word in turn and write down the first word it made them think of. The instructions emphasized that there were no right or wrong answers and that it was important to put down the first word that came to mind. The subjects were asked to respond to all of the stimulus words and then to go back to the beginning and write a short sentence or phrase next to each response to explain the connection they saw between the stimulus and their response

The 50 subjects were friends and relatives of 18 members of an experimental methods class at Trenton State College who each solicited volunteers from among their friends and relatives and who collected the data as part of a class exercise. The subjects performed the association task in a quiet location under the supervision of the experimenter. The subjects were randomly assigned to one of the two lists with the restriction that, for each experimenter, the two lists were used equally often.

Scoring. Responses were classified in terms of their relation to the stimulus using the relation categories listed in Table 1. The criteria for category responses (e.g., bird:robin, robin:bird) were that one word be more general than the other and the two words could

Table 1

Taxonomy of Relations Used to Classify Associative Responses to Nouns

\section{Semantically Rejated}

Synonym

Category

Coordinate

Defining attribute

Characteristic attribute

Thematic

Verb

Part-whole car:auto

robin:bird, bird:robin

armoire:dresser

din:loud

mint:green

tailor:suit

thief:steal

finger:hand, hand:finger

Nonsemantically Related

Same sound

Sound mediated

Completion

Misinterpretation

No identifiable relation be used in the frame, " $A \mathrm{~W}_{1}$ is a kind of $\mathrm{W}_{2}$." Responses were classified as synonyms (e.g., baby:newborn) if the two words could be used to refer to the same thing and could be used in the frame, "A $\mathrm{W}_{1}$ is the same as $\mathrm{W}_{2}$." Coordinates (e.g., tiger:lion) were two words that could be used to refer to similar kinds of things. Responses were classified as defining attributes if they described a property possessed by all instances of the concept (e.g., din:loud) and as characteristic attributes if they described properties possessed by some but not all of the referents of the noun (e.g., mint:green, belt: leather). Thematic relations were two nouns that are typical arguments of the same verb or that refer to actors or props in the same standard event (e.g., tailor:suit). A standard event was any situation that a speaker of English might be expected to recognize (e.g., tailors sewing suits). Verb responses were classified if the response was a verb for which the stimulus noun was a typical argument (e.g., thief:steal). Partwhole responses were classified if the two words could be used in the frame, "W $\mathrm{W}_{1}$ is part of $\mathrm{W}_{2}$ " and similar expressions (e.g., finger: hand).

Nonsemantically based responses were classified into six categories. Same-sound responses rhymed with, sounded the same as, or looked the same as part or all of the stimulus word (e.g., paramour: paramount, paramour:armor). Sound-mediated responses were associates of same-sounding words that acted as mediators (e.g., persimmon: spice are related via the similar sounding mediator cinnamon, which is a kind of spice). Responses were classified as having no identifiable relation if the event to which they referred appeared to be idiosyncratic or could not be identified (e.g., tear:itch). Completions were responses based on a word that was part of a stock sequence or phrase (e.g., turtle:dove). Morphological responses were cases in which the subject gave a morphological variant of the same root word (e.g., entomology:entomologist). Misinterpretations were cases in which the subject gave the stimulus word an interpretation that was legitimate but not the one intended by the experimenter (e.g., hazel:Smith).

Two judges, one of whom was blind with respect to the experimental hypothesis, independently classified the responses. The agreement rate was $81.2 \%(\mathrm{kappa}=0.78)$. Differences were reconciled by discussion. Agreement on classification into the three broad categories of definitional, event-based, and nonsemantic responses was $92.9 \%(\mathrm{kappa}=0.89)$.

\section{Results}

Semantically related responses. Table 2 gives the mean probability of a semantically related response being related to the stimulus by one of eight types of semantic relation. Probabilities were calculated for each subject separately for high- and low-familiarity words by dividing the frequency of each relation by the overall frequency of semantically related responses. Low-familiarity stimuli were more likely to elicit category (e.g., osteopath:doctor) and coordinate (e.g., armoire:dresser) responses than were high-familiarity stimuli, whereas high-familiarity stimuli were more likely to elicit thematic (e.g., axe:wood), verb (e.g., bumblebee:sting), and characteristic attribute (e.g., bathrobe:blue) responses. Relations that were elicited in different proportions by high- and low-familiarity stimuli are indicated in the tables by an asterisk placed next to the higher probability.

The differences were evaluated by an analysis of variance (ANOVA) with familiarity (high and low) and relation type (seven levels) as repeated measures factors. Four features of this analysis will also apply to all of the analyses reported below. (1) For all differences reported, $p<.05$, except where noted. (2) Because the levels of relation type were not independent, multivariate statistics are re- 
Table 2

Mean Probability (Frequency of Relation/Frequency of Semantically Related Responses) of Different Types of Semantic Relation as a Function of Familiarity in Experiment 1

\begin{tabular}{lcc}
\hline \multicolumn{1}{c}{ Relation Type } & Unfamiliar & Familiar \\
\hline Definitional & & \\
Category & $.55^{*}$ & .22 \\
Synonym & .06 & .03 \\
Coordinate & $.07^{*}$ & .01 \\
Attribute defining & .04 & .03 \\
Event-Based & & \\
Thematic & .17 & $.34^{*}$ \\
Verb & .02 & $.14^{*}$ \\
Attribute characteristic & .05 & $.16^{*}$ \\
Part-whole & .05 & .06 \\
\hline
\end{tabular}

*Significant difference between unfamiliar and familiar category members.

ported for effects involving this variable. (3) Analyses were also performed with an arcsine transformation applied to the probabilities to correct for the low frequencies in some cells; these analyses are reported only when the results differ from those for the probabilities, in which case, the outcome of the arcsine analysis is preferred. (4) In analyses of semantically related responses, one relation type was omitted from the analysis so that the probabilities for the remaining relation types would not sum to 1.0 and provide no variability in the means. The relation selected for omission was one for which there were few responses and, unless otherwise mentioned, for which there was no effect of familiarity. Synonym responses were omitted from the analysis of these data.

The interaction of familiarity with relation type was significant $[F(6,44)=20.88$, Wilks's lambda $=.26]$, as was the main effect of relation type $[F(6,44)=66.77$, Wilks's lambda $=.10]$. Simple effects tests showed that differences between high- and low-familiarity stimuli were significant for category $\left[F(1,49)=74.01, M S_{\mathrm{e}}=0.08\right]$, coordinate $\left[F(1,49)=7.44, M S_{\mathrm{e}}=0.01\right]$, thematic $\left[F(1,49)=20.28, M S_{\mathrm{e}}=0.07\right]$, verb $[F(1,49)=36.73$, $\left.M S_{\mathrm{e}}=0.02\right]$, and characteristic attribute $[F(1,49)=$ 28.93, $\left.M S_{\mathrm{e}}=0.02\right]$ responses.

The top row of Table 3 shows the probability of a response being semantically related to the stimulus (frequency of relation/frequency of all responses). Highfamiliarity stimuli were more likely to elicit semantically related responses than were low-familiarity stimuli $[F(1,49)$ $\left.=139.55, M S_{\mathrm{e}}=0.03\right]$. The subjects who did not know the meaning of a low-familiarity stimulus necessarily responded on the basis of its physical characteristics. Nonsemantically related responses were, thus, more frequent for low-familiarity stimuli than for high-familiarity stimuli. For this reason, the data were presented in Table 2 as a proportion of semantically related responses, not as a proportion of all responses.

Nonsemantically related responses. In addition to showing the probability of semantically related responses, Table 3 shows the probability of nonsemantically related responses (frequency of relation/frequency of all responses), classified in terms of five categories of nonse- mantic relation. Low-familiarity stimuli elicited a greater proportion of same-sound responses, sound-mediated responses, mistakes, and responses with no identifiable relation to the stimulus. The only type of nonsemantic response that was more frequent for high-familiarity stimuli was completions.

The differences were analyzed by an ANOVA in which familiarity and relation type (five levels) were withinsubjects variables. The interaction of familiarity and relation was significant $[F(4,46)=26.13$, Wilks's lambda $=$ $.31]$, as were the main effects of familiarity $[F(4,196)=$ $\left.139.55, M S_{\mathrm{e}}=0.01\right]$ and relation $[F(4,46)=5.95$, Wilks's lambda $=.66]$. Simple effects tests showed that the difference between high- and low-familiarity stimuli was significant for same-sound responses $[F(1,49)=26.95$, $\left.M S_{\mathrm{e}}=0.03\right]$, sound-mediated responses $[F(1,49)=87.62$, $\left.M S_{\mathrm{e}}=0.01\right]$, misinterpretations $\left[F(1,49)=9.14, M S_{\mathrm{e}}=\right.$ $0.01]$, responses with no identifiable relation to the stimulus $\left[F(1,49)=23.24, M S_{\mathrm{e}}=0.02\right]$, and completions $\left[F(1,49)=14.32, M S_{\mathrm{e}}=0.01\right]$.

\section{Discussion}

Semantically related responses. Low-familiarity words elicited a higher proportion of defining responses, whereas high-familiarity words elicited a higher proportion of event-based responses. This definition effect supports the hypothesis that people attend more to definitional relations for unfamiliar words than for familiar words and is contrary to the event-based hypothesis, which predicted the opposite result. Low-familiarity words elicited a higher proportion of category (e.g., osteopath: doctor) and coordinate (e.g., armoire:dresser) responses. Category superordinates represent most clearly the type of information about word meaning that we have characterized as definitional, and so we will tentatively label these three relations as definitional. High-familiarity stimuli, in contrast, elicited more thematic (e.g., axe: wood), verb (e.g., bumblebee:sting), and characteristic attribute (e.g., bathrobe:blue) responses. Thematic and verb responses represent the clearest case of event-based relations, and we will tentatively identify these three relations as event-based.

Could the definition effect be due to uncontrolled differences between the high- and low-familiarity stimuli?

Table 3

\begin{tabular}{|c|c|c|}
\hline Relation Type & Unfamiliar & Familiar \\
\hline Semantically Related & 48 & $.87^{*}$ \\
\hline \multicolumn{3}{|l|}{ Nonsemantically Related } \\
\hline Same sound & $.14 *$ & .01 \\
\hline Sound mediated & $.16^{*}$ & .01 \\
\hline Misinterpretation & $09^{*}$ & .01 \\
\hline No identifiable relation & $.13^{*}$ & .03 \\
\hline Completion and morphological & .00 & $.07^{*}$ \\
\hline
\end{tabular}

*Significant difference between unfamiliar and familiar category members. 
This possibility cannot be entirely ruled out, although high-and low-familiarity stimuli came from the same taxonomic categories so that most of the factors, such as imageability and concreteness, that might confound the comparison were held constant. Nevertheless, in Experiment 2, the semantic difference between high- and lowfamiliarity stimuli was narrowed still further by comparing high- and low-familiarity synonyms.

There is no reason to think, apart from the present results, that low-familiarity category members are associated more strongly with their superordinates than are high-familiarity members. Instead, the opposite relationship might have been expected. Larochelle and Pineau (1994) found a positive but nonsignificant relation between frequency and category dominance (the frequency of production of a category as the superordinate of an instance), which is, in turn, positively related to item dominance (the frequency with which an instance is given as an example of a category; see Anderson \& Reder, 1974, Chumbley, 1986, and Loftus \& Scheff, 1971). For this reason, item dominance (production frequency) was equated for high- and low-familiarity stimuli.

Nonsemantically related responses. Semantically unrelated responses were more frequent for low-familiarity stimuli. This was to be expected, given that, for most subjects, some of the low-familiarity words would have been totally unfamiliar. In these cases, a subject would have to respond not on the basis of meaning but on the basis of the physical properties of the stimulus words (Durso \& Shore, 1991; O'Connor, 1940).

Sound or appearance appears to have been the basis for many of these responses. For example, same-sound (e.g., persimmon:permission, mead:knead) and sound-mediated (e.g., tarantella:spider, persimmon:spice) responses were more frequent for low-familiarity stimuli. In the latter case, the subjects explained that "tarantella sounds like a poisonous spider [tarantula]" and that the stimulus persimmon "sounds like cinnamon." Responses classified as having no relation to the stimulus were also more frequent for lowfamiliarity stimuli. Some of these responses may have been mediated by the sound of the stimulus in ways the judges could not identify.

Completions (e.g., honey:dew) were treated as nonsemantic responses because they do not depend on the meaning of the stimulus word, but on familiarity with the concatenation. Completions occurred more frequently for high-familiarity stimuli than for low-familiarity stimuli. Familiarity with the concatenation is clearly required for this type of response and may be correlated with familiarity with the words that make up the sequence.

Sound-mediated responses. Sound-mediated responses provide an opportunity to compare memory and processing explanations of the definition effect. For soundmediated responses, the familiarity of the stimulus and the representation of meaning responsible for the associate are dissociated (e.g., the stimulus persimmon elicited the response spice from several subjects who had thought of the same-sounding word, cinnamon, which is a kind of spice). These subjects were responding to a low-familiarity stimulus on the basis of a higher familiarity semantic representation. If the definition effect is due to the familiarity of the semantic representation from which the response is drawn, then the effect will not occur for soundmediated responses. If the effect is due to processing, then it may appear in sound-mediated responses, because low-familiarity stimuli elicit a shift of processing resources toward definitional associates of same-sounding mediators (e.g., a subject who does not know the meaning of persimmon and thinks instead of cinnamon may be more likely to attend to definitional associates of cinnamon-e.g., spice - than to event-based associates-e.g., apple pie).

Sound-mediated responses were further classified as definitional or event-based on the basis of the relation between the same-sounding mediator and the response. The classifications were based on the direction of the definition effect for responses directly related to the stimulus: Category, synonym, coordinate, and defining attribute responses were classified as definitional; all other semantically related responses were classified as eventbased. Three judges were asked to identify a mediating word that sounded like the stimulus word and that could have formed the basis for the subject's response. In many cases, identification of the mediator was not difficult because the subjects explicitly referred to it in their explanations. For example, one subject gave the association rickets:fence and explained, "I thought of 'picket." The relation between the mediator and the subject's response was classified as definitional, event-based, or other.

Two of the three judges identified the same mediating word for $96.0 \%$ of the 112 sound-mediated responses. Of these, 105 were responses to low-familiarity stimuli. For these, the relation of mediator and response was classified as definitional $(n=64)$, event-based $(n=15)$, or nonsemantically related $(n=26)$. The mean written frequency of the mediators identified by the judges $(M=7.37, S D=$ 18.80 ) was higher than that of both the low-familiarity stimuli and the high-familiarity stimuli, although not significantly different from either.

The probability of a definitional response was higher than for responses that were directly associated by a semantic relation to the low-familiarity stimulus. For comparison, the probability of a definitional sound-mediated response was computed by dividing the frequency of definitional sound-mediated responses by the frequency of semantically related sound-mediated responses. This probability $(.81)$ was similar to and somewhat higher than that for semantically related responses to unfamiliar stimuli (.73).

The results for the sound-mediated responses supported the processing account of the definition effect. For lowfamiliarity stimuli, the proportion of definitional relations for sound-mediated responses was similar to that for semantically related responses. This is the outcome predicted by the processing explanation. The definition effect may be due to a shift of processing resources to definitional information in the presence of a low-familiarity stimulus. This conclusion must be viewed with caution, 
since these responses represent only $17 \%$ of responses to low-familiarity stimuli. They were not, however, restricted to a few subjects or a few stimuli; they came from 39 subjects, in response to 19 stimuli.

\section{EXPERIMENT 2}

In Experiment 2, familiarity was varied by selecting pairs of high- and low-familiarity nouns from the same synonym set (e.g., baby, neonate, newborn). It seems likely that when a person encounters a new member of a synonym set, she/he might focus on other members of the set as a means of establishing its meaning. If so, then, in Experiment 2, low-familiarity stimuli would be expected to elicit a greater proportion of synonym responses rather than category responses. This would indicate that the type of definitional relation that predominates depends on the organization of the semantic field to which a word belongs. The use of synonyms also provided a somewhat closer match of the meaning of high- and lowfamiliarity stimuli than in Experiment 1 . A definition effect in Experiment 2 would thus strengthen the conclusion that the effect was due to familiarity rather than to some uncontrolled covariate.

A third purpose of Experiment 2 was to determine whether the definition effect obtained in Experiment 1 is restricted to the particular stimulus word under consideration while the response is made. If the effect is due to selective processing of definitional information, exposure to low-familiarity words may lead to a shift of attention toward defining relations for all stimuli in a task. Exposure to only high-familiarity words might lead to a general shift of focus away from definitional and toward event-based relations. To examine this possibility, in Experiment 2 , a between-subjects design was used in which the subjects saw either high- or low-familiarity synonyms. In addition, all subjects saw the same high-frequency filler words. If exposure to low- or high-familiarity words induces a general set to focus more on defining or eventbased relations, then we would expect the group exposed to low-familiarity synonyms to give a greater proportion of defining responses to the filler words and the group exposed to high-familiarity synonyms to give a greater proportion of event-based responses to the same words. A definition effect for filler words would strongly suggest that the definition effect was due to a processing effect rather than a memory effect.

\section{Method}

Materials. A preliminary selection of 60 synonym pairs was made so that one member of each pair was judged to be familiar and the other unfamiliar. The 60 unfamiliar words were randomly ordered and presented in a booklet to 20 subjects, who rated them for familiarity on a 5-point scale labeled extremely familiar (5), moderately familiar (4), slightly familiar (3), moderately unfamiliar (2), and extremely unfamiliar (1).

From this list, 20 words were selected that had received familiarity ratings between 3.5 and 1.7 (i.e., they were rated as slightly to moderately unfamiliar; $M=2.88, S D=0.52$ ). These served as the low-familiarity synonyms. These were each paired with a syn- onym of higher written frequency. The mean written frequency of the low-familiarity synonyms $(M=0.90$; Francis \& Kučera, 1982) was substantially lower than that of the high-familiarity synonyms $(M=123.85)\left[t(24)=3.18, S E_{\mathrm{D}}=172.78\right]$. An additional 20 familiar filler words were selected of slightly lower frequency than the high-familiarity synonyms $(M=64.8)\left[t(24)=1.36, S E_{\mathrm{D}}=\right.$ 194.61]. The stimuli are listed in Appendix B. Five additional synonym pairs and filler words were selected in a similar fashion to serve as practice stimuli.

High-familiarity and low-familiarity lists were prepared. Each consisted of 20 experimental stimuli and 20 filler words, randomly ordered, preceded by 10 practice stimuli. The same order was used for all subjects.

Procedure. The procedure was similar to that for Experiment 1 except that the subjects were given the instruction to write an explanation for each response after completing the associations. The subjects were 42 students in an introductory psychology class at Trenton State College who participated as part of an instructional exercise. They were randomly assigned to the high- or low-familiarity synonym group.

Scoring. Two judges, one of whom was blind with respect to the experimental hypothesis, independently classified the responses in terms of their relation to the stimulus, using the relation categories listed in Table 1 . The agreement rate was $80.0 \%(\mathrm{kappa}=.77)$. Agreement on classification into the three broad categories of definitional, event-based, and nonsemantic relations was $88.5 \%$ $(\mathrm{kappa}=.82)$.

\section{Results}

Semantically related responses. Table 4 shows the probability of a semantically related response being related to the stimulus by one of eight types of semantic relation (frequency of relation/frequency of semantically related responses) for the experimental and filler items The experimental items showed a definition effect similar to that observed in Experiment 1. The low-familiarity synonym group gave a greater proportion of synonym responses (e.g., butte:cliff, megalopolis:city) and defining attributes (e.g., megalopolis:huge, din:loud), whereas the high-familiarity synonym group gave a greater proportion of thematically related responses (e.g., bowl: cereal, noise:headache), verbs (e.g., book:read, gun:kill), and part-whole responses (e.g., shoe:heel, baby:family). Responding to the filler items was unaffected by the familiarity of the experimental items and was similar to that for the high-familiarity experimental items.

The data were evaluated by an ANOVA in which familiarity was a between-subjects factor and relation type (eight levels) and item type (synonym or filler) were within-subjects factors. Antonym responses were omitted from the analysis. The three-way interaction was significant $[F(7,34)=6.32$, Wilks's lambda $=.43]$, as was the main effect of relation type and all of its interactions, which are not reported here. The comparisons of interest are those between the high- and low-familiarity groups for each relation. These were performed separately for experimental and filler items. For the experimental stimuli, synonyms made up a larger proportion of responses for the low-familiarity group than for the high-familiarity group $\left[F(1,40)=15.16, M S_{\mathrm{e}}=0.05\right]$. There was also a tendency for the low-familiarity group to give a greater proportion of defining attribute responses $[F(1,40)=$ 
Table 4

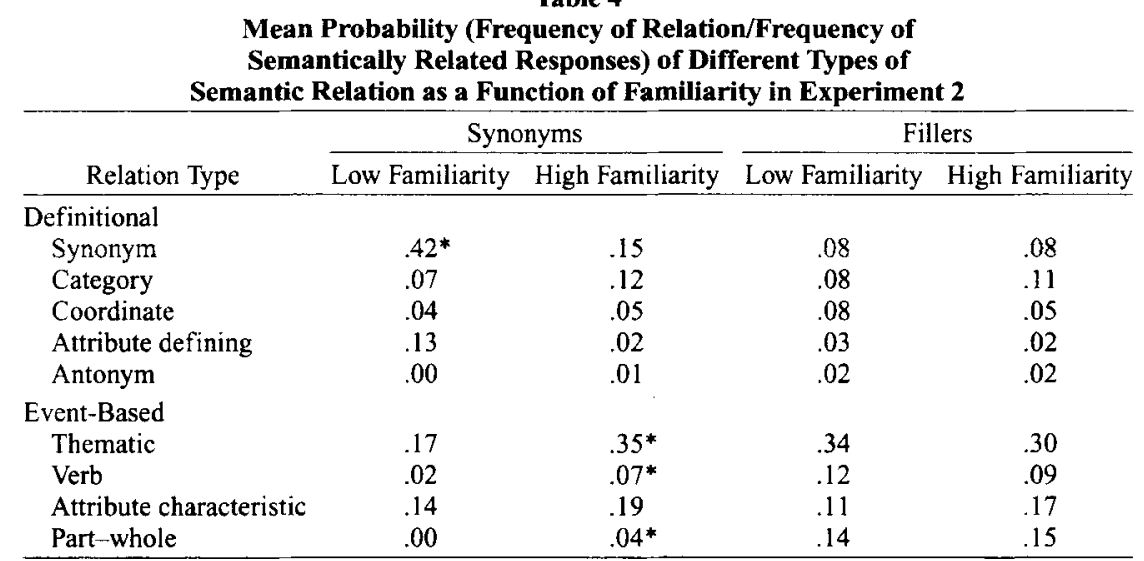

*Significant difference between high- and low-familiarity synonyms.

4.22, $M S_{\mathrm{e}}=0.03$ ]; however, this difference did not reach significance when the data were analyzed with an arcsine transformation $\left[F(1,40)=3.27, M S_{\mathrm{e}}=0.07, p=.08\right]$. In contrast, the high-familiarity group gave a greater proportion of thematically related $\left[F(1,40)=15.39, M S_{\mathrm{e}}=\right.$ $0.02], \operatorname{verb}\left[F(1,40)=6.82, M S_{\mathrm{e}}=0.01\right]$, and part-whole $\left[F(1,40)=10.47, M S_{\mathrm{e}}=0.001\right]$ responses.

For the filler stimuli, there were no differences between the two groups in the proportion of responses of each relation type. Part responses accounted for a greater proportion of responses to filler stimuli than to experimental stimuli $\left[F(1,40)=73.91, M S_{\mathrm{e}}=0.01\right]$. This can be attributed to the inclusion among the filler stimuli of two names of parts, verse and prefix, that elicited a large number of wholes as responses.

Might the greater frequency of synonym responses to low-familiarity synonyms have been an artifact of how the low-frequency synonyms were selected? Synonym pairs were selected in which one word was of high familiarity and the other was of low familiarity. Suppose that the high- and low-familiarity synonyms are both members of a set of synonyms. If any member of the synonym set is presented as a stimulus, then other members of the set may be given as a response, with the probability being higher for high-familiarity members of the set than for low-familiarity members. When a high-familiarity member of the set is presented as a stimulus, this member of the set is no longer available as a response, and so the probability of a synonym response is lower. In contrast, when a low-familiarity member of the set is presented as a stimulus, the high-familiarity synonym is still available to be given as a response, and so the probability of a synonym response is higher. This would result in a higher frequency of synonym responses to low-familiarity synonyms.

In order to evaluate this possibility, responses that corresponded to the high-familiarity synonym stimulus for each pair were excluded, and synonym responses were recounted for the low-familiarity group. For example, two of the synonyms selected as stimuli were cleric (low familiarity) and priest (high familiarity) from the synonym set, which also included clergyman. In recounting, the response priest was excluded. (It was not necessary to perform this recount for the high-familiarity group since the high-familiarity synonym did not occur as a response to itself.) One third of synonym responses to low-familiarity synonym stimuli corresponded to the high-familiarity stimulus (e.g., priest, probability $=.14$ ). The remaining synonym responses were other members of the same synonym set (e.g., clergyman, probability $=.29$ ). Counting only these remaining responses, synonyms were still more than twice as likely in the low-familiarity group (.29) than in the high-familiarity group (.15), and the difference was significant $\left[F(40)=4.06, M S_{\mathrm{e}}=0.05\right]$.

The top row of Table 5 shows the probability of a response being semantically related to the stimulus (frequency of relation/frequency of all responses). The proportion of semantically related responses was lower for low-familiarity stimuli than for high-familiarity stimuli or filler items, resulting in significant effects of group $\left[F(1,40)=93.01, M S_{\mathrm{e}}=0.02\right]$ and item type $[F(1,40)=$ $\left.87.28, M S_{\mathrm{e}}=0.01\right]$ and their interaction $[F(1,40)=$ $\left.121.63, M S_{\mathrm{e}}=0.01\right]$.

Nonsemantically related responses. In addition to showing the probability of semantically related responses, Table 5 shows the probability of nonsemantically related responses (frequency of relation/frequency of all responses), classified in terms of five categories of nonsemantic relation. Semantically unrelated responses were more frequent for low-familiarity stimuli than for highfamiliarity stimuli.

Low-familiarity synonyms received a higher proportion of same-sound responses, sound-mediated responses, misinterpretations, and responses with no identifiable relation. Only for completions were values higher for lowfamiliarity synonyms. The probability of nonsemantically related responses was evaluated by an ANOVA in which group was a between-subjects variable and item type and relation type were within-subjects variables. All main effects and two-way interactions were significant and are not described here. More importantly, the three-way interaction was significant $[F(4,37)=43.39$, Wilks's lambda $=.16]$. Comparisons between the two groups were, there- 
Table 5

Mean Response Probability (Frequency/Frequency of All Responses) of Semantically Related and Different Types of Nonsemantically Related Responses as a Function of Relation and Familiarity in Experiment 2

\begin{tabular}{lccccc}
\hline \multirow{2}{*}{$\begin{array}{c}\text { Relation of Response } \\
\text { to Stimulus }\end{array}$} & \multicolumn{2}{c}{ Synonym } & & \multicolumn{2}{c}{ Filler } \\
\cline { 2 - 3 } \cline { 5 - 6 } \cline { 5 - 6 } $\begin{array}{l}\text { Semantically related } \\
\text { Nonsemantically related }\end{array}$ & .25 & $.87^{*}$ & & .78 & .82 \\
$\quad$ & & & & & \\
Same sound & $.23^{*}$ & .00 & & .02 & .00 \\
Sound mediated & $.15^{*}$ & .00 & & .00 & .00 \\
Misinterpretation & $.04^{*}$ & .00 & & .04 & .04 \\
No identifiable relation & $.28^{*}$ & .01 & & .01 & $.03 *$ \\
Completion & .04 & .11 & & .14 & .11 \\
\hline
\end{tabular}

*Significant difference between high- and low-familiarity synonyms.

fore, made for each type of nonsemantic relation for experimental and filler items. For the experimental items, the low-familiarity group made more same-sound responses $\left[F(1,40)=28.20, M S_{\mathrm{e}}=197.88\right]$, more soundmediated responses $\left[F(1,40)=43.92, M S_{\mathrm{e}}=0.01\right]$, more misinterpretations $\left[F(1,40)=16.21, M S_{\mathrm{e}}=0.001\right]$, and more responses with no identifiable relation $[F(1,40)=$ $\left.23.66, M S_{\mathrm{e}}=0.03\right]$. The tendency for the high-familiarity group to make more completion responses did not reach significance $\left[F(1,40)=3.53, M S_{\mathrm{e}}=0.03, p=.07\right]$.

There was one difference between the two groups for the filler items: Responses with no identifiable relation were more common in the high-familiarity group than in the low-familiarity group for filler items, while the reverse was true for experimental items $\left[F(1,40)=7.56, M S_{\mathrm{e}}=\right.$ $0.001]$.

\section{Discussion}

Low-familiarity nouns elicited more defining and fewer event-based responses than did high-familiarity nouns. When the subjects saw a word whose meaning they were unsure of, the first word that came to mind was one with the same meaning. This result was consistent with the results of Experiment 1 in supporting the definition hypothesis. The effect cannot be readily attributed to uncontrolled differences in concreteness, imageability, or semantic properties since pairs were selected from the same synonym set. Nor can it be attributed to a generally greater availability of high-familiarity synonyms as responses to the low-familiarity stimuli, since it occurred even when responses that corresponded to the high-familiarity stimulus were excluded.

Semantically related responses. Synonym responses were more frequent for low-familiarity synonyms. The frequency of category responses was unaffected by familiarity. This is in contrast to the finding in Experiment 1, where category responses were affected by familiarity and synonym responses were not. The difference appears to be due to the organization of the semantic fields to which the two sets of stimuli belonged. Stimuli in Experiment 2 belonged to synonym sets, whereas stimuli in Experiment 1 belonged to taxonomic categories. In Experiment 2, the defining relation that was most available was synonymy; in Experiment 1, it was category superordinates. Whether synonym or category responses predom- inate appears to depend on how the local semantic field is organized. For some fields, the organization is taxonomic, and the superordinate provides the most available definitional associates. For others, the organization is in terms of a synonym set, and the most available definitional associates are synonyms.

Sound-mediated responses. As in Experiment 1, the subjects gave a substantial number of sound-mediated responses (e.g., hovel:spacecraft), and these were further classified as definitional or event-based. Two out of three judges agreed in identifying a mediating word that sounded the same as the stimulus (e.g., Hubble) related to the response (e.g., spacecraft) for $64(96.9 \%)$ of the sound-mediated responses. The majority of these responses $(n=61)$ were made by subjects in the low-familiarity group responding to low-familiarity synonyms. The following description deals with these responses, which were made by 20 of the 21 subjects in the low-familiarity group in response to 18 of the 20 low-familiarity stimuli. The mean written frequency of the mediators identified by the judges $(M=12.02, S D=20.87$; Francis \& Kučera, 1982) was intermediate between the low-familiarity stimuli $(M=0.90, S D=1.83)$ and the high-familiarity stimuli $(M=123.85, S D=173.08)$.

The relation between mediator and response was classified as definitional $(n=29)$, event-based $(n=28)$, or nonsemantically related $(n=4)$. When these frequencies are expressed as probabilities (frequency of relation/ frequency of semantically related response to the mediator), the probability of definitional responses (.51) was midway between the values observed for unfamiliar synonyms (.67), and familiar synonyms (.34), and filler items (.29). This result does not differentiate between the memory and processing accounts of the definition effect.

Context effects. Use of a between-subjects design allowed us to see whether the tendency of low-frequency stimuli to elicit definitional associates might induce a set to respond to other, more familiar, stimuli in a similar fashion. A definition effect for filler words would have suggested that the effect was due to processing, not to memory differences between high- and low-familiarity words. There was, however, no evidence for a context effect of this sort. The absence of a context effect for the filler items means that the mechanism responsible for the definition effect operates in response to individual words. 
This conclusion is consistent with either a memory or a processing explanation of the effect.

The only effect of context on the experimental items was that the high-familiarity group made more responses with no identifiable relation for the filler items. There is no obvious explanation for this effect. Whatever its source, it does not provide evidence of the kind of strategic shift of attention between definitional and event-based information that the experiment was designed to detect.

\section{EXPERIMENT 3}

The purpose of Experiment 3 was to examine the eventbased and definition hypotheses for verbs. Event-based relations may be more important in the representation of verb meaning than in that of noun meaning (Chaffin \& Fellbaum, 1996). The meaning of verbs is closely linked with the nouns that serve as their typical arguments. This is suggested by three observations. First, the noun arguments of a verb are influential in selecting its meaning (Gentner \& France, 1988). Second, verbs elicit a larger proportion of syntagmatic associations than do nouns (Cramer, 1968, p. 67; Fillenbaum \& Jones, 1965; Rosenweig, 1970, p. 102). The nouns that occur as responses to verbs are typical arguments of the verb (e.g., eat:food). Third, the possible meanings of a new verb are constrained by its argument structure (Fisher, Gleitman, \& Gleitman, 1991; Gleitman \& Gleitman, 1992; Schwanenflugel, Fabricius, Noyes, Bigler, \& Alexander, 1994). These observations point to the importance of event-based relations in the representation of verb meaning. The definition effect observed for nouns in Experiments 1 and 2 may, therefore, not occur for verbs.

As in Experiment 2, the semantic characteristics of high- and low-familiarity stimuli were equated by selecting pairs of synonyms. It was noted above that the use of synonyms as stimuli raises the possibility that a lower proportion of synonym responses to familiar words could be an artifact due to the low familiarity of the most likely definitional associate for high-familiarity stimuli. This possible artifact was eliminated in Experiment 3 by selecting stimulus pairs for which a third, high-frequency synonym could be identified (e.g., prognosticate and foretell were selected as low- and high-familiarity synonyms, and predict was identified as an additional highfamiliarity synonym). This ensured that a high-familiarity definitional response was available for both high- and low-familiarity stimuli. The subjects who were presented with foretell as a stimulus and who did not know the word prognosticate could still respond with the synonym predict. If the proportion of definitional responses is lower to foretell than to prognosticate, this will not be attributable to the lack of an available high-familiarity definitional response for foretell.

\section{Method}

Materials. Twenty verb synonym pairs were selected to serve as stimuli. One word in each pair was low in familiarity, and one was high. As far as possible, words were selected that did not also have a meaning as a noun. Words that did have a noun sense (e.g., ridicule) were selected only if their frequency of use as verbs was higher than their frequency as nouns (Francis \& Kučera, 1982). For each pair, a high-frequency third synonym was identified. The stimuli are listed in Appendix C.

The synonym pairs were selected from a longer list of 53 pairs that were randomly ordered and presented in a booklet to 21 subjects, who rated them for familiarity on a 5-point scale, as in Experiment 2. The low-familiarity synonyms were rated lower in familiarity $(M=$ $3.16)$ than the high-familiarity stimuli $(M=4.95)[t(19)=19.32$, $S E_{\mathrm{D}}=.32$ ]. The low-familiarity synonyms were also lower in written frequency $(M=1.55)$ than the high-familiarity stimuli $(M=$ $14.50)\left[t(19)=2.74, S E_{\mathrm{D}}=21.11\right.$; Francis \& Kučera, 1982]. The mean frequency of the third synonym identified for each synonym pair was higher than that for the high-familiarity stimuli $(M=45.00)$ $\left[t(19)=2.07, S E_{\mathrm{D}}=65.82\right]$.

Procedure. Two lists were created, each containing one word from each of the 20 experimental pairs. Half of the words on each list were high in familiarity, and half were low. Synonym pairs were counterbalanced across lists. Both lists began with the same four practice items. Half of the subjects responded to one list, and half responded to the other.

The procedure was similar to that for Experiment 1 except that the subjects were told that the stimuli were verbs and were not told that they would have to give an explanation for their responses until after the association task had been completed. Also, the subjects were given the option of not providing an explanation for responses that involved personal matters that they did not want to explain.

Forty-two undergraduates of Furman University (Greenville, SC) did the association task, and 21 different individuals provided familiarity ratings. The subjects participated to fulfill a course requirement.

Classification of responses. Responses were classified independently by two judges who had not been involved in the earlier experiments, and one of whom was not aware of the experimental hypothesis. The agreement rate was $82.3 \%(\mathrm{kappa}=.76)$.

Responses were first classified as nouns, verbs, or other syntactic class. Disagreements were assigned the syntactic classification that had the highest frequency in the Francis and Kučera (1982) frequency norms. The responses were then classified in terms of their relation to the stimulus using the relation categories listed in Table 6.

Verb responses were classified into five types of verb:verb relations identified on the basis of the taxonomy of these relations described by Fellbaum (1990). Responses were classified as similar if they were synonyms (e.g., soothe:calm), troponyms (e.g., confiscate: take), or cotroponyms (commandeer:hijack) of the stimulus and fit one of the sentence frames, " $V_{1}$ ing is the same as $V_{2}$ ing," " $V_{1}$ ing is to $V_{2}$ in a particular manner," and " $V_{1}$ ing and $V_{2}$ ing are both manners/ ways of $\mathrm{V}_{3}$ ing something." Responses were classified as antonyms (e.g., delete:add) if they fit the frame, " $\mathrm{V}_{1}$ ing is the opposite of $\mathrm{V}_{2}$ ing" and were classified as proper inclusion (recuperate:sleep) if they fit the frame " $V_{2}$ ing is part of $V_{1}$ ing." Responses were classified as backward presupposition/cause (e.g., foretell:foresee) if they fit the frames, "Before you $V_{1}$, you have to have $V_{2}$, $d$," " $V_{1}$ ing someone/thing may cause them/it to $\mathrm{V}_{2}$," or " $\mathrm{V}_{1}$ ing may cause you to $\mathrm{V}_{2}$." Verb responses were defined as event-based (e.g., putrefy: disgust) if they were not otherwise classified into one of the above categories and referred to an action that might normally occur as part of the same standard event as the stimulus verb.

Noun responses were classified according to the following criteria: Agents (e.g., foretell:seer) were nouns that are typical animate instigators of the action or state identified by the stimulus verbs. Themes/recipients were nouns referring to things that typically undergo change as a result of the action (e.g., soothe:ache) or to animate beings affected by the action or state (e.g., revere:God). Locations (e.g., recuperate: hospital) were nouns identifying the location, spatial orientation, or setting of the action. Event-based responses (e.g., 
Table 6

Taxonomy of Relations Used to Classify Associative Responses to Verbs in Experiment 3

Semantically Related

\begin{tabular}{ll}
$\begin{array}{l}\text { Definitional Relations } \\
\text { Similarity }\end{array}$ & $\begin{array}{l}\text { soothe:calm, decay:rot (synonym) } \\
\text { confiscate:take, abscond:leave (troponym) } \\
\text { commander:hijack (cotroponym) } \\
\text { delete:add, strengthen:weaken } \\
\text { recuperate:sleep, putrefy:stink }\end{array}$ \\
$\begin{array}{ll}\text { Antonymy } \\
\text { Proper inclusion } \\
\text { Backward presupposition } \\
\text { and cause }\end{array}$ & $\begin{array}{l}\text { foretell:foresee, reproduce:mate } \\
\text { feed:eat, give:have }\end{array}$ \\
$\begin{array}{ll}\text { Event-Based Relations } \\
\text { Event-based verbs }\end{array}$ \\
$\begin{array}{ll}\text { Agent } & \text { petrify:disgust, sell:cost } \\
\text { Theme/recipient } & \text { foretell:seer, dominate:chief } \\
\text { Location } & \text { soothe:ache, revere:god } \\
\text { Other event-based nouns } & \text { recuperate:hospital, enroll:school } \\
& \text { convalesce:wheelchair, foretell:crystal ball } \\
& \text { Nonsemantically Related } \\
\text { Same sound } & \text { garner:garnish, bleach:beach } \\
\text { Sound mediated } & \text { garner:cook, propitiate:rain } \\
\text { Misinterpretation } & \text { revere:paul, excise:tax } \\
\text { Completion } & \text { sleep:walk, go:get } \\
\text { No identifiable relation } & \text { espouse:rhyme, revere:stoic }\end{array}$ \\
\hline
\end{tabular}

convalesce:wheelchair) were nouns referring to things that are part of a standard event involving the action or state referred to by the verb and that were not classified in one of the categories listed above.

Nonsemantically based responses were classified into the same categories as in the previous experiments.

\section{Results}

Semantically related responses. Table 7 shows the probability of a semantically related response being related to the stimulus by one of nine types of semantic relation (frequency of relation/frequency of semantically related responses).

There was a definition effect similar to that obtained in the previous experiments. Low-familiarity verbs elicited a greater proportion of verbs with similar meaning (e.g., soothe: calm, confiscate: take). High-familiarity verbs elicited more verbs related by backward presupposition and cause (e.g., foretell:foresee) and more nouns that function as typical themes for the stimulus verbs (e.g., foretell: future). There was also a trend for nouns referring to typical locations (e.g., recuperate:hospital) to be more probable for high-familiarity verbs.

Differences were analyzed by ANOVAs in which familiarity (two levels) and relation type (eight levels) were within-subject factors. The small number of antonym responses and data from 7 subjects who made no semantically related responses at one level of familiarity were omitted from the analyses. There was an interaction of relation type and familiarity $[F(7,28)=7.86$, Wilks's lambda $=.34$, as well as a main effect of relation type $[F(7,28)=29.44$, Wilks's lambda $=.12]$. Simple effects tests showed that the effect of familiarity was significant for verbs related by similarity $\left[F(1,34)=6.36, M S_{\mathrm{e}}=\right.$ $0.14]$ and backward presupposition or cause $[F(1,34)=$ $\left.15.11, M S_{\mathrm{e}}=0.02\right]$ and for nouns related as typical themes
$\left[F(1,34)=15.02, M S_{\mathrm{e}}=0.03\right]$. The effect for locations $\left[F(1,34)=3.92, M S_{\mathrm{e}}=0.01, p=.056\right]$ approached significance, whereas that for event-based verb responses did not $(F<1.0)$.

The selection of verbs from semantic fields containing three synonyms was successful in ensuring that definitional associates were available for high- and lowfamiliarity stimuli (e.g., the synonym stimuli garner and accumulate elicited the high-familiarity synonym that had been identified, collect, and also elicited gather, add, and get as other similarity verb responses). In response to the high-familiarity stimuli, the subjects gave the word identified as the alternate high-frequency synonym on 15 occasions; the low-familiarity synonyms selected as stimuli were never given as responses. In response to the low-familiarity stimuli, the high-familiarity synonym selected as a stimulus was given on only five occasions. The frequency of this response was too low to account for the difference in the proportion of similarity responses for high- and low-familiarity stimuli.

The top row of Table 8 shows the probability of a response being semantically related to the stimulus (frequency of relation/frequency of all responses). As in Experiments 1 and 2, high-familiarity stimuli received a higher proportion of semantically related responses $\left[F(1,49)=184.84, M S_{\mathrm{e}}=345.22\right]$.

Nonsemantically related responses. Table 8 also shows the probability of nonsemantically related responses (frequency of relation/frequency of all responses), classified in terms of five categories of nonsemantic relation.

Differences were evaluated in an ANOVA in which familiarity (two levels) and relation type (six levels) were within-subjects factors. The interaction of familiarity with relation type was significant $[F(5,37)=63.88$, Wilks's lambda $=.10]$, as were the effects of familiarity $\left[F(1,41)=184.84, M S_{\mathrm{e}}=57.54\right]$ and relation type $[F(5,37)=55.49$, Wilks's lambda $=.12]$. Simple effects tests showed that low-familiarity stimuli elicited more same-sound responses $\left[F(1,41)=56.21, M S_{\mathrm{e}}=0.05\right]$, sound-mediated responses $\left[F(1,41)=39.87, M S_{\mathrm{e}}=\right.$ $0.03]$, and responses with no identifiable relation $\left[F(1,41)=35.43, M S_{\mathrm{e}}=0.02\right]$. High-familiarity stimuli

Table 7

Mean Probability (Frequency of Relation/Frequency of Semantically Related Responses) of Different Types of Semantic Relation as a Function of Familiarity in Experiment 3

\begin{tabular}{lll}
\multicolumn{1}{c}{ Relation Type } & Unfamiliar & Familiar \\
\hline Verbs & $.54^{*}$ & .38 \\
Similarity & .01 & .01 \\
Antonymy & .10 & .06 \\
Proper inclusion & .01 & $.11^{*}$ \\
Backward presupposition & .06 & .02 \\
Event-based & & \\
Nouns & .03 & .06 \\
Agent & .03 & $.14^{*}$ \\
Theme+recipient & .02 & $.05^{*}$ \\
Location & .18 & .17 \\
Event &. .17 \\
\hline
\end{tabular}

* Significant difference between unfamiliar and familiar synonyms. 
Table 8

Mean Response Probability (Frequency/Frequency of All Responses) of Semantically Related and

Different Types of Nonsemantically Related Responses as a Function of Familiarity in Experiment 3

\begin{tabular}{lcc}
\multicolumn{1}{c}{ Relation Type } & Unfamiliar & Familiar \\
\hline Semantically Related & .28 & $.83^{*}$ \\
Nonsemantically Related & & \\
Same sound & $.30^{*}$ & .04 \\
Sound mediated & $.21^{*}$ & .03 \\
No identifiable relation & $.15^{*}$ & .02 \\
Misinterpretation & .04 & $.08^{*}$ \\
Completion & .00 & .00 \\
Morphological & .02 & .01 \\
\hline
\end{tabular}

*Significant difference between unfamiliar and familiar synonyms.

elicited more misinterpretations $\left[F(1,41)=5.78, M S_{\mathrm{e}}=\right.$ $0.01]$.

\section{Discussion}

Verbs showed a definition effect similar to that observed for nouns in Experiments 1 and 2. Low-familiarity stimuli elicited a higher proportion of defining responses. The relations that are most clearly definitional for verbs are the three similarity relations: synonymy (e.g., soothe: calm), troponymy (e.g., walk:saunter), and cotroponymy (e.g., saunter:shuffle). Any of these relations would be likely to appear as part of a verb's definition.

High-familiarity verbs elicited more event-based responses. Responses that are most clearly event-based for verbs are the nouns that serve as their typical arguments when the verbs are used to talk about events, including themes (e.g., soothe:ache) and locations (e.g., recuperate: hospital). High-familiarity verbs also elicited more verbs related by backward presupposition (e.g., foretell:foresee) and cause (e.g., feed:eat), two relations that reflect the temporal organization of events. This was surprising, since these were expected to function as definitional relations. Verbs related by backward presupposition and cause are in a verb implication relation (Fellbaum \& Miller, 1990) that would appear to be important in defining the verbs that they relate (Chaffin \& Fellbaum, 1996). The two relations do, however, reflect the temporal organization of events.

Sound-mediated responses were further classified as definitional or event-based, as in the previous experiments. Two judges agreed in identifying a mediating word (e.g., precipitate) that sounded the same as the stimulus word (e.g., propitiate) and that was related to the response (e.g., rain) for $55(85.9 \%)$ of the sound-mediated responses. Of these responses, 52 were to low-familiarity stimuli. These responses were made by 26 subjects $(61 \%)$ to 17 of the low-familiarity stimuli and accounted for $20 \%$ of the responses to low-familiarity stimuli. The mean written frequency of the mediators $(M=17.28, S D=22.84)$ was slightly higher than that for the high-familiarity stimuli $(M=14.50, S D=21.04)$.

The relation between the mediator and response was classified as definitional $(n=29)$, event-based $(n=19)$, or nonsemantically related $(n=4)$. The probability of definitional responses (frequency of relation/frequency of semantically related responses to the mediator) was 60 . This is closer to the value for low-familiarity stimuli (.65) than that for high-familiarity stimuli (.45). The results thus support the processing account of the familiarity effect.

\section{EXPERIMENT 4}

Experiments 1-3 demonstrated an effect of familiarity on type of association; they did not, however, manipulate familiarity directly. Differences between high- and low-familiarity words were minimized by selecting pairs from the same category or synonym set, but the possibility that the definition effect was due to some uncontrolled difference other than familiarity cannot be entirely ruled out. Experiments 4 and 5 were designed to remedy this problem by including novel words. The subjects first read context sentences, each containing a target word that was novel (a nonsense word) or was either low or high in familiarity. For example,

The tourists rode in a $\left\{\begin{array}{l}\text { taxi } \\ \text { kaptim } \\ \text { rickshaw }\end{array}\right\}$ through the city streets.

The subjects then gave associations to the target words they had just seen. If we find the same definition effect as in the earlier experiments, this will suggest more strongly that the effect is due to familiarity and that it occurs when a novel word is first encountered.

Pilot studies indicated that, in order for subjects to remember the meanings of the novel words, only a small number of sentences could be presented at one time and that subjects had to be encouraged to pay close attention to the novel words. As a result, subjects were presented with six context sentences at a time and were asked to use the target word in a sentence immediately after reading each context sentence. Subjects were told that later tasks would require them to remember the target words.

After the association task, subjects were asked to recall the context sentence and to generate a superordinate for each target word. This provided a measure of whether event-based information (recall) or definitional information (superordinate) was available for each target word shortly after the association test. Associations were also scored for whether they had appeared in the context or generated sentences. According to the event-based hypothesis, associations to novel words will be based on the sentence in which the word was initially encountered or on the event that it described. This view predicts that associations to novel words will contain a high proportion of words from either the context or the generated sentences.

We were concerned that these additional measures might influence subjects' responses in the association task, by suggesting that either superordinates or words from the context sentence were the associations that were important to the experimenters. To evaluate the role of these possible demand characteristics, subjects in Experiment 4 saw only one set of six sentences and completed the as- 
sociation task before doing the superordinate generation sentence recall task. There was thus no opportunity for these latter two tasks to affect responding in the association task. Since each subject saw only two sentences at each familiarity level, it was necessary to evaluate the data from Experiment 4 in the context of those from Experiment 5 , which presented a larger number of items to each subject.

\section{Method}

Subjects. Twelve members of a research methods class at Trenton State College first participated in the experiment as subjects and then each solicited 11 additional volunteers to serve as additional subjects from among their friends, relatives, and co-workers. A total of 144 subjects participated in the experiment.

Materials. Twenty-four taxonomic categories were selected from the Battig and Montague (1969) category norms. A highfrequency word and a low-frequency word were selected from each category to serve as target words. A nonsense word was generated for each of the 24 sets of words to serve as target words that would be compietely unfamiliar to all subjects. Each category was thus represented by target words representing three levels of familiarity: high familiarity, low familiarity, and nonsense. The target words were rated for familiarity by 18 additional subjects on the 5-point scale used in the earlier studies. High-familiarity words were rated as extremely familiar $(M=4.40)$, low-familiarity words were rated as slightly familiar $(M=2.95)$, and novel words were rated as extremely unfamiliar $(M=1.05)$.

A context sentence was generated for each set of stimulus words so that when the sentence contained the nonsense word, its meaning could be inferred and the low- and high-familiarity words paired with the nonsense word also fit meaningfully into the sentence (e.g., The tourists rode in a taxi/rickshaw/kaptim, through the city streets). To verify this, 28 additional subjects read the context sentences containing the nonsense words and generated a superordinate for the nonsense word in each. The context sentences and the three target words for each are listed in Appendix D.

Procedure. The 24 sentences were randomly divided into four sets of 6. Three forms of each set were created so that across forms each context sentence appeared with its corresponding high-familiarity, low-familiarity, and nonsense target words. Within each set of 6 sentences there were 2 high-familiarity, 2 low-familiarity, and 2 nonsense words.

Each subject performed five tasks: sentence generation, free association, explanation of the associative relation, superordinate production, and sentence recall. Each task was presented on a separate page in the booklet. The subjects completed each task for all six target words before moving on to the next task. The target words were presented in the same random order in each task for all subjects.

For the sentence generation task, the subjects read each of the context sentences in which the target word was capitalized. They were instructed to write a new sentence describing an imaginary event using the capitalized word. They were told that the purpose of the task was to ensure that they read the context sentence and understood it because later parts of the experiment would require them to be familiar with the sentence and the capitalized word.

For the association task, the context words were listed, and the subjects were instructed to read each word and to write down next to it the first word that it made them think it. Two additional words appeared at the beginning of the list to serve as practice items. After completing the association task, the subjects were asked to go back to the beginning of the list and write a brief explanation of the relation between each response and stimulus word.

For the superordinate generation task, the subjects were asked what kind of thing each of the target words referred to. For the mem- ory task, the subjects were asked to recall the context sentence for each target word.

Scoring. Association responses were classified according to the classification scheme used in Experiments 1 and 2, with three changes. Category, synonym, and coordinate responses were classified in a single class: category responses. For novel words, there was no basis for distinguishing these three types of responses since we did not know exactly what meaning the subjects inferred from the context sentence. For high- and low-familiarity words, the majority of responses falling into this class were superordinates. In addition, a category of other semantically related responses and a category of nonsemantically related comment responses were added. Responses were classified as misinterpretations if the subject had assigned the target word a meaning different from that intended, as indicated by the response in the sentence generation or superordinate generation tasks. These were treated as nonsemantically related responses since they were not related to the intended meaning of the stimulus.

Association responses were classified in two stages. One classification was made by members of the class that collected the data. Six pairs of judges each independently classified the responses of 24 subjects each and resolved disagreements by discussion. The judges were blind to the purpose of the experiment when making these classifications and when collecting the data. A second independent classification was provided by a single judge who classified all of the responses. The agreement rate between this judge and the classification of the first pair of judges was $85.2 \%$ (kappa $=$ .79). Disagreements were decided by the author

Responses in the superordinate generation task were assigned a score on a 4-point scale by a single judge: the response was the superordinate that the experimenters intended (3), was not the superordinate intended but was a plausible inference from the context sentence (2), was not a plausible inference (1), and no response (0).

\section{Results}

Association task. As in the previous experiments, the results suggested the operation of a definition strategy. Low-familiarity and novel words elicited higher proportions of category responses, whereas high-familiarity words elicited higher proportions of thematic, verb, attribute, and part responses. The probabilities of the various semantically related responses are shown in Table 9 (frequency of relation/frequency of semantically related responses). A similar pattern of differences also appeared when the data were examined as frequencies. The small numbers of defining and characteristic attributes were combined into a single category of attribute responses. There were no defining attribute responses to novel and low-familiarity words, and there were only a very small number for high-familiarity words $(M=.02)$.

The differences were evaluated by a repeated measures ANOVA in which familiarity (three levels) and relation type (five levels) were within-subjects factors. The category of other responses was omitted from the analysis. Data for 29 subjects who made no semantically related responses for one or more levels of familiarity were omitted from the analysis. The interaction of familiarity with relation type was significant $[F(8,107)=9.04$, Wilks's lambda $=.99]$, as was the main effect of relation type $[F(4,456)=130.16$, Wilks's lambda $=.16]$. Analytical comparisons showed that high-familiarity stimuli received a smaller proportion of category responses than 
Table 9

Mean Probability (Frequency of Relation/Frequency of Semantically Related Responses) of Different Types of Semantic Relation as a Function of Familiarity in Experiments 4 and 5

\begin{tabular}{|c|c|c|c|c|c|c|}
\hline \multirow[b]{2}{*}{ Relation Type } & \multicolumn{3}{|c|}{ Experiment 4} & \multicolumn{3}{|c|}{ Experiment 5} \\
\hline & Novel & Low Familiarity & High Familiarity & Novel & Low Familiarity & High Familiarity \\
\hline \multicolumn{7}{|l|}{ Category, synonym, and } \\
\hline coordinate & $.79^{*}$ & .77 & .45 & $.82^{*}$ & .77 & .54 \\
\hline Attribute and function & .03 & .08 & $.12^{*}$ & .04 & .07 & $.15^{*}$ \\
\hline Thematic & .11 & .09 & $.20^{*}$ & .07 & .12 & .18 \\
\hline Noun:verb & .03 & .02 & $.10^{*}$ & .05 & .02 & .05 \\
\hline Part-whole & .02 & .03 & $.11^{*}$ & .02 & .01 & $.05^{*}$ \\
\hline Other & .01 & .01 & .03 & .00 & .01 & .02 \\
\hline
\end{tabular}

*Significant effect of familiarity.

did low-familiarity stimuli $\left[F(1,114)=59.12, M S_{\mathrm{e}}=0.19\right]$ or novel words $\left[F(1,114)=47.81, M S_{\mathrm{e}}=0.26\right]$. In contrast, high-familiarity stimuli received a higher proportion of thematic responses than did low-familiarity and novel words $\left[F(1,114)=11.53, M S_{\mathrm{e}}=0.13\right.$, and $F(1,114)$ $=6.51, M S_{\mathrm{e}}=0.26$, respectively], a higher proportion of verbs $\left[F(1,114)=12.75, M S_{\mathrm{e}}=0.05\right.$, and $F(1,114)=$ $8.64, M S_{\mathrm{e}}=0.08$, respectively], and a higher proportion of parts $\left[F(1,143)=9.68, M S_{\mathrm{e}}=0.07\right.$, and $F(1,143)=$ $5.43, M S_{\mathrm{e}}=0.09$, respectively]. For parts, the difference between high-familiarity and novel words showed a trend $\left[F(1,114)=3.65, M S_{\mathrm{e}}=0.19, p=.06\right]$. In addition, high-familiarity stimuli received a higher proportion of attribute responses than did novel word stimuli $\left[F(1,114)=8.17, M S_{\mathrm{e}}=0.11\right]$.

The effects of familiarity were also examined using a nonparametric statistic to determine whether lack of normality in the data may have distorted the results of the analysis. The main feature of the results-the effect of familiarity for category responses-was reliable (Friedman $=33.44$ ), but differences for other relation types were not significant.

Table 10 shows the probability of a response being semantically related to the stimulus and the probability of its being related by one of the different types of nonsemantic relations (frequency of relation/total number of responses). The effect of familiarity on the probability of a semantically related response was significant $\left[F(2,284)=17.09, M S_{\mathrm{e}}=0.06\right]$. High-familiarity stimuli elicited a higher proportion of semantically related responses than did low-familiarity stimuli $[F(1,142)=$
17.41, $\left.M S_{\mathrm{e}}=0.12\right]$ or novel words $[F(1,142)=26.64$, $\left.M S_{\mathrm{e}}=0.15\right]$. The difference between low-familiarity and novel words did not reach significance $[F(1,142)=$ $3.21, M S_{\mathrm{e}}=0.11, p=.07 \mathrm{]}$.

Table 10 also shows the different types of nonsemantically related responses. The small numbers of misinterpretation, no identifiable relation, and comment responses were combined into a single category: misinterpretation responses. High-familiarity words elicited fewer samesound responses, sound-mediated responses, and misinterpretations and more completions than did low-familiarity or novel words. Differences for same-sound and misinterpretation responses were evaluated by an ANOVA with familiarity (three levels) and relation (two levels) as factors. The data for one subject who made no responses of these types for one or more levels of the familiarity variable were not included in the analysis. The interaction of familiarity with relation was significant $[F(2,141)=5.17$, Wilks's lambda $=.93$ ], as were the main effects of familiarity $\left[F(2,284)=22.04, M S_{\mathrm{e}}=0.02\right]$ and relation $\left[F(1,141)=4.31, M S_{\mathrm{e}}=0.05\right]$. High-familiarity stimuli elicited a lower proportion of same-sound and miscellaneous responses than did low-familiarity stimuli $[F(1,142)$ $=26.56, M S_{\mathrm{e}}=0.04$, and $F(1,142)=6.62, M S_{\mathrm{e}}=0.03$, respectively] or novel words $\left[F(1,142)=24.93, M S_{\mathrm{e}}=\right.$ 0.08 , and $F(1,142)=9.54, M S_{\mathrm{e}}=0.03$, respectively $]$.

To determine the degree to which associations to novel words were based on the context in which they had been previously encountered in the experiment, associative responses generated by each subject were classified as to whether they had appeared in the context sentence

Table 10

Mean Response Probability (Frequency/Frequency of All Responses) of Semantically Related and Different Types of Nonsemantically Related Responses as a Function of Familiarity in Experiments 4 and 5

\begin{tabular}{|c|c|c|c|c|c|c|}
\hline \multirow[b]{2}{*}{ Relation Type } & \multicolumn{3}{|c|}{ Experiment 4} & \multicolumn{3}{|c|}{ Experiment 5} \\
\hline & Novel & Low Familiarity & High Familiarity & Novel & Low Familiarity & High Familiarity \\
\hline $\begin{array}{l}\text { Semantically Related } \\
\text { Nonsemantically Related }\end{array}$ & .75 & .80 & $.92 *$ & .75 & .83 & $.90^{*}$ \\
\hline Same sound & $.12^{*}$ & .10 & .01 & $.14^{*}$ & .09 & .02 \\
\hline Sound mediated & .07 & .05 & .00 & $.04^{*}$ & .05 & .00 \\
\hline Completions & .00 & .00 & .06 & .00 & .00 & .05 \\
\hline $\begin{array}{l}\text { Misinterpretation, } \\
\text { no identifiable } \\
\text { relation, and comments }\end{array}$ & $.06^{*}$ & .06 & .02 & $.06^{*}$ & .03 & .02 \\
\hline
\end{tabular}

* Significant effect of familiarity. 
or in the sentence generated by that subject. These sentences were the subjects' only experience with the novel words. If associations to novel words were directly based on these sentences, then we might expect novel words to elicit a higher proportion of words from these sentences than would high-familiarity words. These data are shown in Table 11. For novel words, only $8 \%$ of semantically related responses were words that had appeared in the context sentence; another $8 \%$ had appeared in the generated sentence. In contrast, almost $80 \%$ of responses to novel words were categories. Moreover, there was no tendency for words from the context and generated sentences to appear as associates more frequently for novel words than for familiar words. Rather, the direction of the effects was the opposite. For the generated sentences, there was a trend toward an effect of familiarity $[F(2,228)=2.41$, $\left.M S_{\mathrm{e}}=0.05, p=.09\right]$; words from the generated sentence tended to be more likely to be given as responses to highfamiliarity words than to novel and low-familiarity words $\left[F(1,114)=4.21, M S_{\mathrm{e}}=0.12, p=.04\right.$, and $F(1,114)=$ $3.16, M S_{\mathrm{e}}=0.08, p=.08$, respectively].

Superordinate and recall tasks. The lower probability of event-based associates for low-familiarity and novel stimuli was not due to a lack of available event-based associations for these words. The subjects were able to recall the words from the target sentences for target words at all familiarity levels, and recall was higher for less familiar target words. The third row of Table 11 shows the probability of recalling content words or synonyms of these words from the target sentence. The subjects were able to recall a majority of the content words in the context sentences, and recall was affected by the familiarity of the target word $\left[F(2,286)=24.24, M S_{\mathrm{e}}=0.04\right]$. Recall was better for novel words than for low-familiarity words $\left[F(1,143)=15.56, M S_{\mathrm{e}}=0.09\right]$ and better for low-familiarity words than for high-familiarity words $\left[F(1,143)=13.31, M S_{\mathrm{e}}=0.06\right]$. Thus, the lower probability of event-based associates for low-familiarity and novel stimuli was not due to the subjects being unable to remember the context sentence in which these target words had occurred.

The low probability of definitional associates to highfamiliarity words was, likewise, not due to lack of an avail- able category associate for these words. The subjects generated more appropriate superordinates for highfamiliarity stimuli than for novel stimuli. The fourth line of Table 11 shows the mean appropriateness of responses in the superordinate generation task, with higher values indicating more appropriate responses. The subjects were able to generate appropriate superordinates most of the time, and appropriateness increased with familiarity $\left[F(1,143)=14.43, M S_{\mathrm{c}}=0.50\right]$. Responses were more appropriate for high-familiarity words than for lowfamiliarity words $\left[F(1,143)=5.69, M S_{\mathrm{e}}=0.70\right]$ and more appropriate for low-familiarity words than for novel words $\left[F(1,143)=9.01, M S_{\mathrm{e}}=1.23\right]$.

\section{EXPERIMENT 5}

Experiment 5 repeated Experiment 4, with subjects seeing four sets of sentences and performing the association, sentence memory, and superordinate generation tasks after each set. If the results of Experiment 5 are similar to those of Experiment 4, this would indicate that the demand characteristics created by the memory and generation tasks did not affect performance and that the small number of observations in each cell in Experiment 4 did not provide a distorted picture of the outcome. One other change was made in Experiment 5 connected with the concern about demand characteristics. Subjects performed the memory task before the superordinate task. If the ordering of these two tasks suggested that one type of relation was more important than another, placing the memory task first should suggest that the context sentence was more important than the superordinate and might encourage subjects to give more associations based on the former. To the extent that demand characteristics did affect association responses, this would bias the results against finding a definition effect.

\section{Method \\ Subjects. The subjects were 36 students of Trenton State College who participated as part of a course requirement \\ Materials. The stimulus words were the same as those in Ex- periment 4 . The context sentences were altered so that the target word occurred in the first half of the sentence, but no earlier than the third word of the sentence, and the information about its meaning ap-}

Table 11

Mean Probability (Frequency/Frequency of Semantically Related Responses) of Association Responses Appearing in Context or Generated Sentence, Mean Probability of Recalling Content Words From Context Sentence, and Mean Appropriateness of Superordinate Generated in Experiments 4 and 5

\begin{tabular}{|c|c|c|c|c|c|c|}
\hline & \multicolumn{3}{|c|}{ Experiment 4} & \multicolumn{3}{|c|}{ Experiment 5} \\
\hline & Novel & Low Familiarity & High Familiarity & Novel & Low Familiarity & High Familiarity \\
\hline \multicolumn{7}{|l|}{ Association Task } \\
\hline Context sentence & .08 & .07 & .05 & .03 & .09 & $.07^{*}$ \\
\hline Generated sentence & .08 & .13 & .15 & .12 & .27 & .22 \\
\hline \multicolumn{7}{|l|}{ Recall Task } \\
\hline Probability of recall & $.52^{*}$ & .45 & .35 & $.50^{*}$ & .48 & .39 \\
\hline Superordinate Generation Task & & & & & & \\
\hline Appropriateness & 2.31 & 2.58 & $2.75^{*}$ & 2.66 & 2.64 & 2.74 \\
\hline
\end{tabular}

*Significant effect of familiarity 
peared after the target word. The context sentences and stimuli are listed in Appendix E.

Procedure. The procedure was similar to that in Experiment 4 except that each subject saw all four sets of context sentences and target words, and the order of the experimental tasks was different. Familiarity level for the 24 categories was counterbalanced as in Experiment 4, and order of presentation of the four sets was counterbalanced across subjects using a Latin square design.

The subjects read the first set of context sentences, generating a sentence using the target word for each. They then gave an association for each target word, recalled the context sentences, and generated a superordinate. These four tasks were then done in the same order for each of the remaining three sentence sets. After completing the four sentence sets, the subjects turned back in the booklet to their association responses and wrote a rationale for each response.

Scoring. The association responses were classified independently by two judges. One judge was blind as to the purpose of the experiment and had not served as a judge for previous experiments. The second judge was the same person who classified all of the responses for Experiment 4. The agreement rate was $88.8 \%$ (kappa $=82.6$ ).

\section{Results}

Association task. Results were similar to those in Experiment 4 . Low-familiarity and novel words elicited higher proportions of category responses, whereas highfamiliarity words elicited higher proportions of attribute and part responses. The probabilities of the different types of semantic relations (frequency of relation/frequency of semantically related responses) are shown on the righthand side of Table 9. As in Experiment 4, defining and characteristic attributes were combined into a single category. Again, there were no defining attribute responses to novel words and only a very small number for highfamiliarity words $(M=.02)$.

The differences were evaluated by a repeated measures ANOVA with familiarity (three levels) and relation (five levels) as factors. Data for 3 subjects who made no semantically related responses for one level of familiarity were omitted from the analysis. The interaction of familiarity with relation type was significant $[F(8,25)=$ 5.12 , Wilks's lambda $=.34$ ], as was the main effect of relation type $[F(4,29)=244.97$, Wilks's lambda $=.03]$. Analytic comparisons showed that high-familiarity stimuli received a smaller proportion of category responses than did low-familiarity stimuli $\left[F(1,32)=24.58, M S_{\mathrm{e}}=\right.$ $0.07]$ or novel words $\left[F(1,32)=44.78, M S_{\mathrm{e}}=0.06\right]$. In contrast, high-familiarity stimuli received a higher proportion of attribute responses than did low-familiarity or novel words $\left[F(1,32)=10.59, M S_{\mathrm{e}}=0.03\right.$, and $F(1,32)=$ $15.02, M S_{\mathrm{e}}=0.03$, respectively]. High-familiarity words received a higher proportion of part responses than did low-familiarity words $\left[F(1,32)=6.24, M S_{\mathrm{e}}=\right.$ $0.01]$, and there was a trend in the same direction for novel words $\left[F(1,32)=3.58, M S_{\mathrm{e}}=0.04, p=.07\right]$. A similar pattern of differences also appeared when the data were examined as frequencies.

These were the only significant differences, although there were trends for several thematic and verb responses. High-familiarity words received more thematic responses than did novel words $\left[F(1,32)=8.89, M S_{e}=0.33\right]$. but this difference did not reach significance when the prob- abilities were analyzed with an arcsine transformation $\left[F(1,32)=3.11, M S_{\mathrm{e}}=0.08, p=.09\right]$. The tendency for verb responses to be more likely for high-familiarity words than for low-familiarity words and more likely for low-familiarity words than for novel words did not reach significance $\left[F(1,32)=3.05, M S_{\mathrm{e}}=0.01, p=.09\right.$, and $F(1,32)=3.24, M S_{\mathrm{e}}=0.01, p=.08$, respectively

Table 10 shows, on the right-hand side, the probability of a response being semantically related to the stimulus and the probability of its being related by one of the different types of nonsemantic relations (frequency of relation/ frequency of all responses). The effect of familiarity on the probability of a semantic response was reliable $[F(2,70)=$ $\left.8.77, M S_{\mathrm{e}}=0.02\right]$. The probability of a semantically related response was lower for novel words than for highor low-familiarity words $\left[F(1,35)=7.15, M S_{\mathrm{e}}=0.01\right.$, and $F(1,35)=5.73, M S_{\mathrm{e}}=0.01$, respectively]

Table 10 also shows the probability of different types of nonsemantically related responses. High-familiarity words were less likely to elicit same-sound responses, sound-mediated responses, and misinterpretations than were low-familiarity or novel words. These differences were evaluated by an ANOVA with familiarity (three levels) and relation type (three levels) as factors. The effect of relation type and its interaction with familiarity were not significant, although the effect of familiarity was $\left[F(2,70)=15.63, M S_{\mathrm{e}}=0.01\right]$.

The probability of an association response being a word that had appeared in the context or generated sentence (frequency/frequency of semantically related responses) is shown on the right-hand side of Table 11. For novel words, only $3 \%$ of semantically related responses were words that had appeared in the context sentence, and $12 \%$ had appeared in the generated sentence. In contrast, more than $80 \%$ of the responses to novel words were categories. Moreover, there was no tendency for words from the context or generated sentences to appear as associates more frequently for novel words than for familiar words. Rather, the effects were in the opposite direction. For words from the context sentence, the effect of familiarity was significant $\left[F(2,64)=3.67, M S_{\mathrm{e}}=0.01\right]$; responses to highand low-familiarity words were more likely to have appeared in the context sentence than were responses to novel words $\left[F(1,32)=5.21, M S_{\mathrm{e}}=0.02\right.$, and $F(1,32)=5.98$, $M S_{\mathrm{e}}=0.02$, respectively].

Superordinate and recall tasks. Table 11 also presents the data for the superordinate and recall tasks. Recall was affected by familiarity $\left[F(2,70)=7.46, M S_{\mathrm{e}}=0.02\right]$, being better for context sentences containing novel and low-familiarity words than for sentences containing highfamiliarity words $\left[F(1,35)=8.22, M S_{\mathrm{e}}=0.05\right.$, and $F(1,35)=15.86, M S_{\mathrm{e}}=0.02$, respectively $]$. The appropriateness of responses in the superordinate generation task was unaffected by familiarity.

\section{DISCUSSION OF EXPERIMENTS 4 AND 5}

In both experiments, associations to novel words were similar to those to low-familiarity words and were dif- 
ferent from associations to high-familiarity words. The differences were similar to those obtained in Experiments 1-3. Responses to low-familiarity and novel words were more likely to be category superordinates (e.g., persimmon:fruit); responses to high-familiarity words were more likely to be related thematically (e.g., bumblebee: sting). This result strengthens the conclusion that the definition effect is due to familiarity and not to some other uncontrolled difference between high- and low-familiarity words. Also, the source of the associations given to the novel words could be identified with more confidence than was the case for the low-familiarity words.

The similarity of the results in Experiments 4 and 5 suggests that the results are robust under a range of different conditions. The two experiments differed in the number of sentence sets presented, the order of presentation of the memory and superordinate generation tasks, the wording of the context sentences, the manner in which the subjects were recruited, the testing conditions (individual vs. group), the number of different experimenters, and the number of different judges classifying the responses. None of these factors affected the major features of the results.

The results strongly suggest that the definition effect for word association is due to familiarity. The subjects' only experience with the novel words was the context sentence; their associations were necessarily based on that sentence. In spite of this, the subjects overwhelmingly gave category responses rather than words that had occurred in the context sentence. In both experiments, approximately $80 \%$ of semantically related responses were categories, whereas only $15 \%$ were words that had appeared in the context or generated sentences. The subjects had apparently used the information provided in the context sentence to infer what type of thing the novel word referred to. It was this inference, rather than the context or generated sentence, that was most salient in the association task. Relations between novel words and words occurring in the same context were less important as a source of associations than were inferences about the kind of thing the novel word referred to.

The low salience of the context and generated sentences as a source of associations is further underscored by the effects of familiarity on the probability of responses that had appeared in these sentences. In both experiments, semantically related responses were more likely to have appeared in the context or generated sentence for high-familiarity words than for novel words. This difference was significant in Experiment 5 for context sentences, and there was a trend in Experiment 4 for words appearing in the generated sentence. Recent contexts were, thus, more salient for high-familiarity words than for novel words.

The low probability of associations that had appeared in the context sentences was not due to a failure to remember the context sentence. In Experiment 5, the subjects recalled the context sentences better for novel words than for high-familiarity words. This effect probably reflects the additional processing effort required to understand the context sentence for novel words. The absence of the effect in Experiment 4 may have been due to the lower memory load when the subjects had to recall only one set of sentences.

In a parallel fashion, the lower probability of category responses to high-familiarity stimuli was not due to the subjects' not knowing the superordinate categories of these words. The subjects were able to generate appropriate superordinates for words at every level of familiarity, and, in Experiment 4, the subjects generated more appropriate superordinates for high-familiarity words than for low-familiarity or novel words. Thus, the definition effect in the association task occurred in spite of superordinates being either equally available or somewhat more available for high-familiarity words than for lowfamiliarity and novel words.

\section{GENERAL DISCUSSION}

The results of all five experiments support the definition hypothesis that low-familiarity words would elicit a higher proportion of definitional responses than would high-familiarity words. There was no support for the eventbased hypothesis that low-familiarity words would elicit a higher proportion of event-based responses. In Experiments 1,4 , and 5, novel and low-familiarity words elicited approximately $30 \%$ more category responses (e.g., osteopath:doctor) than did high-familiarity words. In Experiments 2 and 3, low-familiarity words elicited approximately $20 \%$ more synonyms and similars (e.g., armoire:dresser) than did high-familiarity words. Highfamiliarity words, in contrast, elicited more event-based associations-more thematic (e.g., axe:wood) and noun: verb (e.g., bumblebee:sting) responses - than did novel or low-familiarity words. The differences ranged from $30 \%$ in Experiment 1 to $10 \%$ in Experiment 5, with differences of $20 \%$ in Experiments 2 and 4. Similarly, in Experiment 3, verb:noun responses (e.g., foretell:future) were $16 \%$ more probable for high-familiarity verbs than for low-familiarity verbs.

The present data do not directly answer the question of why familiar and unfamiliar words differ in this way. The effect can, however, be attributed to familiarity rather than to some other uncontrolled property of the stimuli. In Experiments 4 and 5, both novel and low-familiarity words elicited a higher proportion of category responses than did high-familiarity words. For novel words, the subjects apparently made inferences that established links with other, more familiar words that were similar in meaning. These definitional links were more salient for novel and lowfamiliarity words than were the corresponding links for familiar words. These definitional links were also more salient for novel and low-familiarity words than were links to other words that had appeared in the same context sentence. In Experiments 4 and 5, words from the same con- 
text sentence accounted for less than $10 \%$ of semantically related associations to novel words, whereas category responses accounted for approximately $80 \%$.

It appears that, when they encountered a novel word, the subjects tried to determine what kind of thing the novel word referred to. This could be an effective strategy for learning the meaning of novel words, because it allows the preexisting lexical organization to assist in determining the meaning of the unfamiliar word. Establishing the semantic field into which a novel word falls allows the meaning of the novel word to be identified in relation to the meanings of other words in the same field (Clark, 1993; Lehrer \& Kittay, 1992). It allows properties ascribed to things of the same kind to be inferred for the novel item. It also allows the formation of hypotheses about differences between the novel word and the more familiar word (Clark, 1993, chap. 3 and 4).

The results were inconsistent with the event-based hypothesis. According to this hypothesis, event-based information should be more salient for novel words than for familiar words. When people encounter a novel word they must attend to the relation between the novel word and other words in the same sentence or other words referring to the same event as the novel word. The context sentence in which a novel word occurs and knowledge about the type of event that it describes provide the only available information about the meaning of the novel word. This kind of event-based information is a necessary basis for forming any inference about the meaning of the novel word. For this reason, we might have expected that, for novel words, event-based links would be established more strongly in memory than would definitional links, and event-based links would be more salient. The results of Experiments 4 and 5 are, however, clearly inconsistent with this idea.

In Experiments 4 and 5, when the subjects first read the context sentence, they must have attended to the relation between the novel word and the other words in the same sentence. The subjects must also have attended to the relation of the novel word to the other words in the sentence that they generated. In spite of this, when the subjects gave an association to the novel word shortly afterward, these event-based associations were not the ones that they gave. Instead, the subjects were more likely to respond with a superordinate that had not appeared in either the context or the generated sentence.

In Experiment 5, the subjects were more likely to give words that had appeared in the context or generated sentence as associates of high-familiarity words rather than of low-familiarity or novel words. This result is striking, given that the context sentence was the subjects' only source of information about the novel word. Moreover, information about the context sentence was available in memory; the subjects had not forgotten the context sentences for novel words. In Experiments 4 and 5, the subjects were able to recall $50 \%-85 \%$ of the content words from the context sentence for novel words. Thus, eventbased associates were available for novel words. Even so, the great majority of associates were definitional. Appar- ently, the definitional information about the meaning of a new word becomes more salient, at a very early stage of the learning process, than does event-based information.

The definition effect occurred in Experiments 4 and 5 for novel words that had just been seen for the first time in a context sentence. In these experiments, the effect can be attributed to the unfamiliarity of the novel word. Since the effect in these experiments was very similar to the effects in Experiments 1-3, the definition effect in Experiments 1-3 may also be attributed to familiarity rather than to some other, uncontrolled difference between the high- and low-familiarity words selected.

The definition effect could be the result of memory or processing, or both. There may be differences in the type of information represented in memory for familiar and unfamiliar words, or there may be differences in the type of information attended to. Different types of information would be stored in memory for familiar and unfamiliar words if the first thing learned about a new word is its similarity in meaning to other, more familiar, words. According to this memory representation account, definitional information is stored first, and eventbased information about the events and situations in the world that the referent of the word co-occurs with is added as familiarity with the word increases. According to this account, the definition effect is due to the greater likelihood of retrieving definitional information for lowfamiliarity words. Alternatively, the familiarity effect may be the result of a processing effect. When an unfamiliar word is encountered, there may be a shift of attentional resources from event-based information to definitional information. This would occur, for example, if encountering an unfamiliar word leads people to shift attention to the task of inferring the meaning of the unfamiliar word, away from the goal of understanding the communicative intention of the utterance in which the word occurred. The result would be an increase in the activation of similarity-based links in memory. In this case, the definition effect would be due to attention to definitional information at the expense of event-based information linked to a word.

The present data do not provide a strong test of these two explanations of the definition effect but are more consistent with the processing explanation. The subjects apparently attended more to definitional information for low-familiarity words, even when event-based information was available in memory. Two results support this interpretation. First, the subjects in Experiments 4 and 5 remembered the context sentences for novel words at least as well as for familiar words. Thus, event-based information was available for novel words. Nevertheless, this information was less likely to be used as a basis for the associative response for novel words. Second, the proportion of definitional responses for sound-mediated responses in Experiments 1 and 3 was similar to the proportion for semantically related responses. For soundmediated responses (e.g., persimmon:spice), the subjects were responding to a low-familiarity stimulus (e.g., persimmon) on the basis of a higher familiarity meaning of 
a similar-sounding word (e.g., cinnamon) for which eventbased information (e.g., cinnamon:apple pie) was presumably available. Familiarity of stimulus word and meaning were thus dissociated. In Experiments 1 and 3 (but not in Experiment 2), the proportion of definitional responses for sound-mediated responses was approximately the same as that for low-familiarity words. This suggests that the definition effect was not due to the lack of event-based information in memory for low-familiarity words (a memory effect) but to the increased salience of definitional information (a processing effect).

Experiment 2 tested one version of the processing explanation by examining the possibility that the presentation of low-familiarity words might lead subjects to give more definitional associations not only to the lowfamiliarity stimuli but to high-familiarity filler items. This did not happen. This outcome is, however, consistent with other versions of the processing explanation in which the switch of attention to definitional relations occurs only for relations with the low-familiarity word and not for other words.

The strongest evidence for the processing interpretation came from the memory task in Experiments 4 and 5 . The subjects remembered the context sentence in which the novel words had occurred. In Experiment 5, they even remembered the sentences better for novel words than for high-familiarity words. The subjects, thus, had event-based associates of the novel words available in memory, but they did not give these associates as responses. This result strongly suggests that the familiarity effect is due to a shift of attentional resources to definitional relations, rather than a lack of event-based information in memory.

\section{Characterizing Definitional and \\ Event-Based Knowledge}

Related distinctions in other studies. The definition effect suggests that there is a functional division of semantic relations into at least two types. The idea of a distinction between two types of associations or two types of knowledge is not new. Wundt (cited in Warren, 1921, pp. 247-248) distinguished relations whose nature is internal to the meaning of a word (e.g., synonymy) from those that depend on factors external to the meaning of the word (e.g., cause-effect). The same distinction is reflected in other taxonomies of relations proposed around the turn of the century (e.g., by Aschoffenburg, Kraeplin, \& Jung, cited in Warren, 1921, pp. 248-250). The distinction between paradigmatic and syntagmatic relations (Cramer, 1968) was probably motivated by similar concerns but was operationalized as membership in the same or a different syntactic class. This resulted in a substantially different distinction that may have served to obscure the definition effect in Deese's (1962) study of the effect of word frequency on type of association. In spite of the intensive study of associations for almost a century, the definition effect reported here was not noted.
More recently, similar distinctions have been frequently made. For example, Miller (1993) has argued that lexical representations include two types of information: semantic and contextual. Semantic knowledge, constituting a definition of a word, is representated by relations between word senses; contextual knowledge is knowledge of the sentence contexts in which the word has been encountered. Similar distinctions, made by other researchers in a variety of fields, are briefly reviewed below.

Sorting tasks. In match-to-sample tasks, children select which of two pictures is most similar to a target picture. For example, the child is shown a picture of a cow and is then asked to select another picture that is "the same kind of thing." The task has been used to compare children's preference for sorting on the basis of what Markman and Hutchinson (1984) call "taxonomic" and "thematic" relations. Preschool children tend to prefer thematic over taxonomic choices (e.g., they select cow:milk over cow:pig; Inhelder \& Piaget, 1964; Sigel, Jarman, \& Hanesian, 1967; for reviews see Carey, 1985, and Markman, 1989, chap. 2). This preference shows an interesting reversal when the child is given a novel name for the target. For example, when a picture of a cow is given a novel name, children select pig, rather than milk, as the same kind of thing. Thus, they shift their attention from thematic to taxonomic relations (Markman \& Hutchinson, 1984; Markman \& Wachtel, 1988; Waxman \& Gelman, 1986). This effect has important similarities to the definition effect observed in the present experiments with adults.

Similarities between different types of relations have been studied by asking subjects to sort examples of a variety of different semantic relations. Chaffin and Herrmann (1984) found three main groups of relations, two of which correspond fairly closely to the present distinction between definitional and event-based relations. Category and similarity relations fell into one group; event and part-whole relations formed a second group. The third group contained examples of contrast relations. Bejar, Chaffin, and Embretson (1991, pp. 78-79) reported a similar study in which subjects sorted 30 word pairs representing 10 different types of semantic relation into two groups. The subjects' sortings corresponded fairly well to a distinction between intensional and pragmatic relations, which is similar to the present distinction between definitional and event-based relations.

Studies of processing differences. Several sets of studies have found processing differences between types of relation that correspond more or less closely to definitional and event-based relations. One line of investigation has examined the conditions under which priming occurs for semantic and associative relations (Hodgson, 1991; Huttenlocher \& Kubicek, 1983; Lupker, 1984; Perea, Gotor, Rosa, \& Algarabel, 1995; Seidenberg, Waters, Sanders, \& Langer, 1984; Shelton \& Martin, 1992). In these studies, semantically related words are category:member pairs, and associatively related words are related in a variety of ways other than categorically; some, it must be assumed, are related by event-based relations. The semantic/ 
associative distinction is thus correlated with the distinction between definitional and event-based relations. This literature suggests that there may be differences between the two types of relation in the type of priming that they produce. Debate continues, but associative priming appears to result automatically from spreading activation, whereas semantic priming appears to be due to strategic processes (Perea et al., 1995; Shelton \& Martin, 1992).

Klix $(1980,1982,1986)$ and his colleagues have conducted a series of studies comparing the processing of two types of relation that they refer to as intraconcept and interconcept relations. Intraconcept relations are computed by a comparison of properties of concepts and include similarity, category, and antonym relations. Interconcept relations are relations that can be directly observed between things in the world, including spatial, temporal, causal, effecting, and intending. Klix and van der Meer (1980) describe a study in which subjects were shown two pairs of words on each trial and then were asked to decide whether the two relations were similar or not. For definitional relations, decisions were faster for word pairs that were higher in rated typicality and rated similarity; for event-based relations, latency was unrelated to typicality or similarity. Klix, van der Meer, and Preuß (1985) found that, for event-based relations, word pairs with a negative affective value were easier to respond to than were neutral pairs, whereas, for definitional relations, the reverse was true. In another study by this group, Hoffmann and Trettin (1980) found that, in a free recall task, subjects clustered terms by either eventbased relations or definitional relations, depending on which type they had been given a set to attend to.

Barr and Caplan (1987) make a related distinction between intrinsic and extrinsic features of concepts. Intrinsic characteristics appear to be based on definitional relations in that they belong to individual instances, considered by themselves (e.g., poodle:dog, ice:cold). A change in an intrinsic relation is a change in the object itself (e.g., if ice were to become warm, then the nature of ice would change). Extrinsic characteristics appear to involve event-based relations in that they are possessed in relation to other things, not by the individual in isolation (e.g., stove:cook, hammer:nail). When an extrinsic characteristic changes, the object itself does not change (e.g., if a stove is used for storing pots instead of for cooking, its nature has not changed, just its use in a particular setting). Barr and Caplan (1987) found that categories differ in the degree to which members are defined by intrinsic and extrinsic features. There was greater agreement on membership judgments, there were steeper membership gradients, and typicality and membership functions were more different for the more intrinsically defined categories than for the more extrinsically defined categories.

Chaffin, Peirce, and Bejar (1990) compared performance on Graduate Record Exam analogy items as a function of major field of study for items based on definitional relations, which they called "intensional," and event-based relations, which they called "extensional." English and history majors performed better on analogies using definitional relations than did electrical engineering and math majors. The opposite was true for analogies using event-based relations. The result suggests that the two types of relation may be engaged to different degrees in different fields of inquiry and that specialized training increases the ability to distinguish one type more than another.

There is thus considerable evidence for a distinction between two broad types of semantic relation from a variety of psychologically significant tasks. Investigators have characterized the distinction differently, depending on their theoretical orientation, and have included somewhat different relations in the two classes, depending on the particular types of materials they were dealing with. There are, however, enough commonalities to suggest that the different investigators are addressing the same distinction.

\section{Characterizing the Distinction From \\ Free Association Responses}

A distinction of some sort between meaning and knowledge is intuitively appealing. One can know about something without having a name for it, and one can know the meaning of a word without knowing everything there is to know about the thing it refers to. However, efforts to draw a boundary between the meaning of a word and knowledge about the real-world objects that the word refers to have never been satisfactory (Haiman, 1980; Levinson, 1983; Tyler, 1978). How do we decide whether the knowledge that tigers have stripes is part of the meaning of the word tiger or just a fact about the class of things we call tigers (Nelson, 1978)?

Comparing free associations to familiar and unfamiliar words allowed us to make a functional distinction between two classes of relations without determining the basis for the distinction. We can now examine the relations that fell into the two classes to try to determine the nature of the functional distinction involved. Some relations behaved consistently across the five experiments, while others behaved less consistently. The category: member relation and synonymy are the two relations that are most clearly important in the definition of a word. These were the two relations that showed the largest and most consistent advantage for low-familiarity words. Thematic and noun:verb relations are the two relations that are most clearly essential to understanding a sentence. These relations were those that showed the largest and most consistent advantage for high-familiarity words. The relevance of other relations, such as attribution and the part-whole relation, to the distinction between definitional and event-based knowledge is less clear, and the results for these relations were less consistent.

Across the five experiments, four types of relation provided a greater proportion of responses for low-familiarity stimuli: category and coordinate responses in Experiment 1, synonymy in Experiment 2, and verb similarity (including troponymy, synonymy, and cotroponymy) in Experiment 3, and category responses (also including co- 
ordinate and synonym responses) in Experiments 4 and 5 . These relations have in common that they are all based on similarity. They are also commonly used in definitions. Categories answer the question, "What kind of thing/ event/state is it?" for nouns (e.g., "A persimmon is a kind of fruit"). Troponyms answer the same question for verbs (e.g., "To confiscate something is to take it in a particular manner"). Synonyms answer the question, "What is it the same as?" for nouns (e.g., "A cleric is the same thing as a priest") and verbs (e.g., "Soothing someone is the same thing as calming someone"). Coordinates answer the question, "What is it similar to?" for nouns (e.g., "An armoire is like a dresser, except that ..."). Cotroponyms answer the same question for verbs (e.g., "Commandeering something is like hijacking it, except that ..."). Attributes are different from these other relations in that they are not based on similarity but are instead a basis for similarity. Attributes can be used to specify what distinguishes one member of a category from other members (e.g., "A din is a loud noise").

One relation that is clearly based on similarity did not appear in our data. There were almost no antonym responses. Antonymy is based on similarity, with contrast on one dimension of meaning (Chaffin \& Herrmann, 1987), and is important in organizing adjective meaning (Gross, Fischer, \& Miller, 1989). Antonymy may function as a defining relation for adjectives. If this proved to be the case, it would support the idea that definitional relations are based on similarity. However, Deese (1962) found that antonyms were more frequent as responses to high-familiarity adjectives than to low-familiarity adjectives, suggesting that antonymy may function as an eventbased relation, a rather counterintuitive result. Deese did not, however, examine frequency as a proportion of semantically based responses. Whether antonymy will show a definition effect remains, therefore, a question for further inquiry.

Across the experiments, seven types of relation provided a greater proportion of responses for high-familiarity stimuli: thematic responses in Experiments 1,2, and 4 (with a trend in Experiment 5), verb responses to nouns in Experiments 1, 2, and 4 (also with a trend in Experiment 5), noun responses to verbs (theme/recipient and location) in Experiment 3, characteristic attributes in Experiment 1, all types of attribute combined in Experiments 4 and 5, and parts in Experiments 2, 4, and 5. In Experiment 3, one verb:verb relation exhibited this pattern (backward presupposition/cause). We can tentatively identify these relations as event-based because they follow the same pattern as the prototypical event-based relations (thematic and noun:verb relations). For thematic and noun:verb relations, there is an identifiable script or frame for a common event that mediates the response (Fillmore \& Atkins, 1992; Schank \& Abelson, 1977). An alternative interpretation of these responses is that they reflect the co-occurrence of the two words in the same sentence. Co-occurrence in the same sentences and cooccurrence in the same events are clearly related. Words that occur together in the same sentence do so because they are used to talk about events in which the referents of the words co-occur. Since the role of events seems more fundamental in forming these relations, I have referred to them as event-based.

Three relations that functioned in the same way as thematic and noun:verb relations are harder to characterize as event-based: backward presupposition and cause (e.g., foretell:foresee, feed:eat), part-whole (e.g., city:street), and characteristic attribute (e.g., bathrobe:blue) relations. Backward presupposition and cause relations were expected to function as definitional relations since they are verb implication relations (Fellbaum \& Miller, 1990) that appear to be important in defining verb meaning (Chaffin \& Fellbaum, 1996). Of the verb implication relations, these two are, however, the relations that most directly reflect the temporal organization of events. Partwhole relations are also not obviously based on events. It is unclear, for example, what event mediates the relation of city and street. On the other hand, the relation is not based on similarity like the definitional relations (Chaffin, 1992; Chaffin \& Herrmann, 1989; Winston, Chaffin, \& Herrmann, 1987). The characteristic attribute relation appears to be based on co-occurrence, although no specific event appears to be involved.

The particular relations that showed the definition effect differed depending on the semantic field from which the words were selected. For example, category responses were more likely to be elicited by low-familiarity words in Experiment 1 but not in Experiment 2, whereas the reverse was true for synonymy. Apparently different relations are more salient as defining relations in different semantic fields. This suggests that there might be semantic fields in which other relations function as defining relations. For example, it is possible that low-familiarity parts (e.g., $j i b$ ) might be more likely to elicit a familiar whole (e.g., sailboat) rather than a familiar category (e.g., sail). If this is the case, then the definition effect does not reflect intrinsic properties of semantic relations (e.g., similarity or contiguity) but rather the function of these relations (i.e., defining meaning or talking about the world). For this reason, I have used the terms definitional and event-based to characterize the two classes, rather than similarity and contiguity.

\section{A Speculation About the Origin of the Definition Effect}

The definition effect reported here is similar to the shift of attention from event-based to definitional relations that occurs with young children in the presence of a novel word. As noted above, in match-to-sample tasks, young children match more on the basis of definitional relations when they encounter an unfamiliar word and more on the basis of event-based relations when they encounter a familiar. This novel-word effect has been interpreted as evidence of a taxonomic constraint that allows young children to solve a fundamental problem of induction: knowing what aspect of the environment an ostensive definition refers to. By focusing on taxonomic relations when they encounter a new word, children are 
predisposed to identify the word as the name for a class of things rather than as the name for a concatenation of aspects of the same event word (Markman, 1989; Markman \& Hutchinson, 1984; Markman \& Wachtel, 1988; Waxman \& Gelman, 1986).

The definition effect may represent a similar constraint that facilitates the learning of new word meanings from linguistic contexts. The novel-word effect for children (Markman, 1989) represents a shift of focus to the denotative relation between a novel word and its referent. The definition effect reported here is a shift of focus to the intensional relations between a low-familiarity word and more familiar words that define its intensional meaning. If the function of the taxonomic constraint is to promote the identification of the referents of new words, then the function of a definition constraint may be to promote the identification of the intension of new words.

\section{REFERENCES}

ANDERSON, J. R., \& REDER, L. M. (1974). Negative judgments in and about semantic memory. Journal of Verbal Learning \& Verbal Behavior, 13, 664-681.

BARR, R. A., \& CAPLAN, L. J. (1987). Category representations and their implications for category structure. Memory \& Cognition, 15, 397-418.

BatTig, W. F., \& MontaGUE, W. E. (1969). Category norms for verbal items in 56 categories: A replication and extension of the Connecticut category norms. Journal of Experimental Psychology Monographs, 80(3, Pt. 2).

Bejar, I. I., Chaffin, R., \& Embretson, S. (1991). Cognitive and psychometric analysis of analogical problem solving. New York: SpringerVerlag.

CAREY, S. (1985). Conceptual change in childhood. Cambridge, MA: MIT Press.

Chaffin, R. (1992). The concept of a semantic relation. In A. Lehrer \& E. Kittay (Eds.), Frames, fields, and contrasts: New essays in semantic and lexical organization (pp. 253-388). Hillsdale, NJ: Erlbaum.

Chaffin, R., \& Fellbaum, C. (1996). The paradigmatic organization of verbs in the mental lexicon. Manuscript submitted for publication.

Chaffin, R., \& Herrmann, D. J. (1984). The similarity and diversity of semantic relations. Memory \& Cognition, 12, 134-141.

Chaffin, R., \& HerrmanN, D. J. (1987). Relation element theory: A new account of the representation and processing of semantic relations. In D. Gorfein \& R. Hoffman (Eds.), Memory and learning: The Ebbinghaus Centennial Conference. Hillsdale, NJ: Erlbaum.

Chaffin, R., \& HerrmanN, D. J. (1989). Retrieval and comparison processes in part-whole decisions. Journal of General Psychology, 116, 393-406.

Chaffin, R., Peirce, L., \& Bejar, I. (1990). Intensional and extensional analogy items: Differences in performance as a function of academic major and sex. Applied Cognitive Psychology, 4, 461-470.

CHumbley, J. I. (1986). The role of typicality, instance dominance, and category dominance. Journal of Experimental Psychology: Learning Memory, \& Cognition, 12, 257-267.

Clark, E. V. (1993). The lexicon in acquisition. Cambridge: Cambridge University Press.

COLE, M. (1990). Cognitive development and formal schooling: The evidence from cross-cultural research. In L. C. Moll (Ed.), Culture communication, and cognition: Vygotskian perspectives (pp. 89-110). Cambridge: Cambridge University Press.

Cramer, P. (1968). Word association. New York: Academic Press.

DEESE, J. (1962). Form class and the determinants of association. Journal of Verbal Learning \& Verbal Behavior, 1, 79-84.

Durso, F. T., \& SHORE, W. J. (1991). Partial knowledge of word meanings. Journal of Experimental Psychology: General, 120, 190-202.

ENTWISLE, D. R. (1966). Word associations of young children. Baltimore: Johns Hopkins University Press.
Fellbaum, C. (1990). English verbs as a semantic net. International Journal of Lexicography, 3, 278-301.

Fellbaum, C., \& Miller, G. A. (1990). Folk psychology or semantic entailment? Comment on Rips and Conrad. Psychological Review, 97, 565-570

Fillenbaum, S., \& Jones, L. V. (1965). Grammatical contingencies in word association. Journal of Verbal Learning \& Verbal Behavior, 4 , 248-255.

Fillmore, C. J., \& Atkins, B. T. (1992). Towards a frame-based lexicon: The semantics of RISK and its neighbors. In A. Lehrer \& E. F. Kittay (Eds.), Frames, fields, and contrasts: New essays in semantic and lexical organization (pp. 75-102). Hillsdale, NJ: Erlbaum.

Fisher, C., Gleitman, H., \& Gleitman, L. R. (1991). On the semantic content of subcategorization frames. Cognitive Psychology, 23, 331-392.

FranCIS, W. N., \& KučERA, H. (1982). Frequency analysis of English usage: Lexicon and grammar. Boston: Houghton Mifflin.

GentNer, D., \& France, I. M. (1988). The verb mutability effect: Studies of the combinatorial semantics of nouns and verbs. In S. L. Small, G. W. Cotrell, \& M. K. Tanenhaus (Eds.), Lexical ambiguity resolution: Perspectives from psycholinguistics, neuropsychology, and artificial intelligence (pp. 343-382). San Mateo, CA: Morgan Kaufman.

Gleitman, L. R., \& Gleitman, H. (1992). A picture is worth a thousand words, but that's the problem: The role of syntax in vocabulary acquisition. Current Directions in Psychological Science, 1, 1-5.

Gross, D., Fischer, U., \& Miller, G. A. (1989). The organization of adjectival meaning. Journal of Memory \& Language, 28, 92-106.

HaIMAN, J. (1980). Dictionaries and encyclopedias. Lingua, 50, 329-357.

Hodgson, J. M. (1991). Informational constraints on pre-lexical priming. Language \& Cognitive Processes, 6, 169-205.

Hoffman, J., \& Tretrin, M. (1980). Organizational effects in semantic relations. In F. Klix \& J. Hoffman (Eds.), Cognition and memorv (pp. 95-102). Amsterdam: North-Holland.

HUTTENLOCHER, J., \& KUBICEK, L. F. (1983). The source of relatedness effects on naming latency. Journal of Experimental Psychology: Learning, Memory, \& Cognition, 9, 486-495.

INHELDER, B., \& PIAGET, J. (1964). The early growth of logic in the child. New York: Norton.

JENKINS, J. J., \& RUSSElL, W. A. (1960). Systematic changes in word association norms: 1910-1952. Journal of Abnormal \& Social Psychology, 60, 293-304.

JENKINS, J. R., STEIN, M., \& WYsocki, K. (1984). Learning vocabulary through reading. American Educational Research Journal, 21, 767-787.

KLIX, F. (1980). On the structure and function of semantic memory. In F. Klix \& J. Hoffman (Eds.), Cognition and memory (pp. 11-25). Amsterdam: North-Holland.

KLIX, F. (1982). Search or inferences: On different modes of knowledge representation. In F. Klix, J. Hoffman, \& E. van der Meer (Eds.), Cognitive research in psychology (pp. 41-54). Amsterdam: North-Holland.

KLIX, F. (1986). Recognition processes in human memory. In F. Klix \& $\mathrm{H}$. Hagendorf (Eds.), Human memory and cognitive capabilities (pp. 321-152). Amsterdam: North-Holland.

KLIX, F., \& vaN DER MEER, E. (1980). The method of analogy recognition for the determination of semantic relations in long-term memory. In F. Klix \& J. Hoffman (Eds.), Cognition and memory (pp. 145-152). Amsterdam: North-Holland.

Klix, F., van der Meer, E., \& Preur, M. (1985). Semantic relations: Recognition effort and pupillary reaction. In F. Klix, R. Näätänen, \& K. Zimmer (Eds.), Psychophysiological approaches to human information processing. Amsterdam: North-Holland.

LeHrer, A., \& KitTAy, E. (EDs.) (1992). Frames, fields, and contrasts New essays in semantic and lexical organization. Hillsdale, $\mathrm{NJ}$ Erlbaum.

Levinson, S. C. (1983). Pragmatics. Cambridge: Cambridge University Press.

Loftus, E. F., \& SchefF, R. W. (1971). Categorization norms for fifty representative instances. Journal of Experimental Psychology Monographs, 91, 355-364.

LUPKER, S. J. (1984). Semantic priming without association: A second look. Journal of Verbal Learning \& Verbal Behavior, 23, 709-733. 
Markman, E. M. (1989). Categorization and naming in children: Problems of induction. Cambridge, MA: MIT Press.

Markman, E. M., \& Hutchinson, J. E. (1984). Children's sensitivity to constraints on word meaning: Taxonomic versus thematic relations. Cognitive Psychology, 16, 1-27.

Markman, E. M., \& Wachtel, G. F. (1988). Children's use of mutual exclusivity to constrain the meanings of words. Cognitive Psychology, 20, 121-157.

McKeown, M. G., Beck, I. L., Omanson, R. C., \& Pople, M. T. (1985). Some effects of the nature and frequency of vocabulary instruction on the knowledge and frequency of word use. Reading Research Quarterly, 20, 522-535.

MiLLeR, G. A. (1993). The association of ideas. The General Psychologist, 29, 69-74.

MoRAn, L. J., MefFerd, R. B., JR., \& Kimble, J. P., JR. (1964). Idiodynamic sets in word association. Psychological Monographs: General \& Applied, 78(2), 1-22.

Nagy, W. E., ANDERSon, R. C., \& Herman, P. A. (1987). Learning word meanings from context during normal reading. American Educational Research Journal, 24, 237-270.

NAGY, W. E., Herman, P. A., \& ANDERSon, R. C. (1985). Learning new words from context. Reading Research Quarterly, 20, 233-253.

NELSON, K. E. (1978). Semantic development and the development of semantic memory. In K. E. Nelson (Ed.), Children's language (pp. 3980). New York: Gardner.

O'ConNor, J. (1940). Unsolved business problems. Boston, MA: Johnson $\mathrm{O}^{\prime}$ Connor Research Foundation.

Perea, M., Gotor, A., Rosa, E., \& Algarabel, S. (1995, November). Time course of semantic activation for different prime-target relationships in the lexical decision task. Paper presented at the annual meeting of the Psychonomic Society, Los Angeles.

Rogoff, B., \& Chavajay, P. (1995). What's become of research on the cultural basis of cognitive development? American Psychologist, 50 859-877.

RosENWEIG, M. R. (1970). International Kent-Rosanoff word associa- tion norms, emphasizing those of French male and female students and French workmen. In L. Postman \& G. Keppel (Eds.), Norms of word association (pp. 95-176). New York: Academic Press.

SCHANK, R. C., \& ABELSON, R. (1977). Scripts, plans, goals, and understanding. Hillsdale, NJ: Erlbaum.

Schwanenflugel, P. J., Fabricius, W. V., Noyes, C. R., Bigler, K. D., \& AleXANDER, J. M. (1994). The organization of mental verbs and folk theories of knowing. Memory \& Language, 33, 376-395.

Seidenberg, M. S. W., Waters, G. S., Sanders, M., \& Langer, P. (1984). Pre- and postlexical loci of contextual effects on word recognition. Memory \& Cognition, 12, 315-328.

Shelton, J. R., \& MARTIN, R. C. (1992). How semantic is automatic semantic priming? Journal of Experimental Psychology: Learning, Memory, \& Cognition, 18, 1191-1210.

SHU, H., ANDERSON, R. C., \& ZHANG, H. (1994). Incidental learning of word meaning while reading: $A$ Chinese and American cross-cultural study (Rep. No. 593). Champaign, IL: Center for the Study of Reading.

Sigel, I., JaRman, P., \& Hanesian, H. (1967). Styles of categorization and their intellectual and personality correspondence in young children. Human Development, 10, 1-7.

STAHL, S. A. (1991). Beyond the instrumentalist hypothesis: Some relationships between word meanings and comprehension. In P. J. Schwanenflugel (Ed.), The psychology of word meanings (pp. 157-186). Hillsdale, NJ: Erlbaum.

STERNBERG, R. J. (1987). Most vocabulary acquisition is learned from context. In M. G. McKeown \& M. E. Curtis (Eds.), The nature of vocabulary acquisition (pp. 89-105). Hillsdale, NJ: Erlbaum.

TYLER, S. (1978). The said and the unsaid. New York: Academic Press. WARREN, H. C. (1921). A history of association psychology. New York Scribner.

Waxman, S., \& Gelman, R. (1986). Preschoolers' use of superordinate relations in classification. Cognitive Development, 1, 139-156.

Winston, M. E., Chaffin, R., \& Herrmann, D. J. (1987). A taxonomy of part-whole relations. Cognitive Science, 11, 417-444.
APPENDIX A

Stimuli for Experiment 1

\begin{tabular}{llll}
\hline \multicolumn{2}{c}{ Experimental } & & \multicolumn{1}{c}{ Filler } \\
\hline Familiar & Unfamiliar & & trampoline \\
kangaroo & ocelot & & shoelace \\
leather & organdy & & trespassing \\
hazel & henna & & cookbook \\
bookshelf & armoire & & ambassador \\
pumpkin & persimmon & & corkscrew \\
boomerang & scythe & & temple \\
boathouse & hacienda & alphabet \\
cocktail & mead & wrinkles \\
axe & awl & & chairman \\
honey & chicory & choir \\
beautician & osteopath & boulder \\
bathrobe & chemise & avalanche \\
bugle & sousaphone & workshop \\
hymn & sonata & crocus \\
rooster & egret & silver \\
seltzer & sarsparilla & night \\
limousine & rickshaw & grandson \\
dentistry & entomology & bridge \\
can can & tarantella & circus \\
mushroom & escarole & campfire \\
asthma & rickets & message \\
raft & frigate & computer \\
anchovy & sturgeon & kite \\
bumblebee & aphid &
\end{tabular}

APPENDIX B

Stimuli for Experiment 2

\begin{tabular}{llll}
\hline \multicolumn{2}{c}{ Experimental } & & \\
\cline { 1 - 2 } Familiar & Unfamiliar & Control \\
\hline lover & paramour & well \\
noise & din & bow \\
belief & certitude & mint \\
baby & neonate & pest \\
whiskey & grog & verse \\
memory & engram & prefix \\
city & megalopolis & circus \\
affair & dalliance & story \\
outrage & umbrage & morning \\
nightmare & incubus & turtle \\
road & mews & omen \\
beam & trestle & relic \\
gun & carbine & image \\
stomach & craw & office \\
mountain & butte & ear \\
priest & cleric & shoe \\
house & hovel & bridge \\
hammer & rammer & peach \\
bowl & tureen & lace \\
hall & anteroom & temple \\
\hline
\end{tabular}




\begin{tabular}{|c|c|c|}
\hline \multicolumn{3}{|c|}{$\begin{array}{c}\text { APPENDLX C } \\
\begin{array}{c}\text { Stimuli and Alternate High-Frequency Synonyms } \\
\text { for Experiment } 3\end{array}\end{array}$} \\
\hline \multicolumn{2}{|c|}{ Experimental Stimuli } & \multirow{2}{*}{$\begin{array}{l}\text { Alternate High- } \\
\text { Frequency Synonym } \\
\text { Available as Response }\end{array}$} \\
\hline Unfamiliar & Familiar & \\
\hline abscond & escape & flee \\
\hline assuage & soothe & ease \\
\hline blanch & bleach & whiten \\
\hline coalesce & combine & merge \\
\hline commandeer & confiscate & seize \\
\hline convalesce & recuperate & recover \\
\hline debauch & deprave & pervert \\
\hline deride & ridicule & scorn \\
\hline espouse & foster & support \\
\hline excise & delete & remove \\
\hline garner & accumulate & collect \\
\hline matriculate & enroll & register \\
\hline prognosticate & foretell & predict \\
\hline proliferate & reproduce & multiply \\
\hline propitiate & soothe & calm \\
\hline putrefy & decay & rot \\
\hline remonstrate & admonish & scold \\
\hline subjugate & dominate & subdue \\
\hline transmute & mutate & change \\
\hline venerate & revere & respect \\
\hline
\end{tabular}

\section{APPENDIX D}

Context Sentences and Target Words for Experiment 4

1. The man quietly strummed a tune on his to relax. asdor/zither/guitar

2. The couple sipped ___ out on the porch. lepity/sarsaparilla/seltzer

3. The captain guided the velisima/yawl/yacht

4. The cashier decided to wear her skirt made of to the restaurant. quantrim/organdy/leather

5 . The waiter mixed a little give it a bitter taste. lipe/chicory/salt

6. The Spaniard did the belevera/tarantella/waltz

in with the coffee beans to towards the dock.

7. The boy contracted quetic/rickets/cholera

8. The cook served the boiled baked potatoes. socourn/kale/cabbage

9. The shoemaker used the leather. turpetlawlineedle

10. The performer played a secoin/fugue/hymn

11. The host spooned the soup from out of the ornate into the bowl. neptle/tureen/bowl

12. The tourists rode in a kaptim/rickshaw/taxi

13. The politician ordered a stisher/drambuie/cocktail until the music stopped. and has since been quite ill. with the steak and to make holes in the on the organ. through the city streets. for everyone at the bar.
14. The woman got up and put on her before going to work. hampell/sari/dress

15. The buzzing of the octen/cicadas/grasshoppers

16. The girl put her the snow. cynthors/mukluks/boots

17. The waitress returned to her the door. proxim/hovel/house

18. The woman went to see a back. clostern/osteopath/doctor

19. The hiker saw a single winniver/grackle/hawk could be heard in the trees. on her feet before going out in r after work and bolted

20. The gardener trimmed the row of way. filpins/yews/holly

21. After stalking its prey the ginto/ocelot/leopard

22. The housewife picked some culperts/guavas/strawberries

23. The gambler fired his

heleager/derringer/pistol
24. The sportsman held the reco about the pain in her perched in the tree. along the drivecaught in the state. bransion/sturgeon/salmon 


\section{APPENDIX E \\ Context Sentences and Target Words for Experiment 5}

1. Joe picked up the asdor/zither/guitar

2. Jill brought the and sipped it with a straw. lepity/sarsparilla/seltzer

3. Kyle had seen the the captain. velisima/yawl/yacht

4. Carol decided that the lovely skirt. quantrim/organdy/leather

5. Jack wondered if the lipe/chicory/salt

6. Kay knew that the ish music. belevera/tarantella/waltz

7. When the was diagnosed, the boy was placed in a hospital. quetic/rickets/cholera

8. Mike was surprised that the socourn/kale/cabbage

in the harbor when he visited could be used to make a

9. First the was used to make holes in the leather. turpet lawlineedle

10. Last night the organist. secoin/fugue/hymn

11. Today the with soup. neptle/tureen/bowl

12. That day the streets. kaptim/rickshaw/taxi

13. Nancy finished her another. stisher/drambuie/cocktail was performed beautifully by the sat ornately on the banquet table filled carried the tourists through the city and asked the bartender for
14. There was the that Ann's seamstress had made for the party. hampell/sari/dress

15. Last night the ___ were buzzing in the trees. octen/cicadas/grasshoppers

16. Jim knew that the ___ would keep his feet warm in the snow. cynthors/mukluks/boots

17. After her the door. proxim/hovel/house

18. Yesterday the ____ examined the pain in Jane's back. clostern/osteopath/doctor

19. There was a single perched in the tree this morning.

winniver/grackle/hawk

20. It is clear that the trimming. filpins/yews/holly

21. Yesterday the the kill. ginto/ocelot/leopard

22. There were culperts/guavas/strawberries

23. After the off. heleager/derringer/pistol

24. Even before the held the record. bransion/salmon/sturgeon along the driveway need stalked its prey and moved in for 